\title{
Therapeutic whole-body hypothermia reduces mortality in severe traumatic brain injury if the cooling index is sufficiently high: meta-analyses of the effect of single cooling parameters and their integrated measure
}

Emoke Olah, MSc, ${ }^{1}$ Laszlo Poto, MSc, PhD, ${ }^{2}$ Peter Hegyi, MD, PhD, DSc, ${ }^{1,3,4}$ Imre Szabo, MD, $\mathrm{PhD},{ }^{3}$ Petra Hartmann, MD, PhD, ${ }^{5}$ Margit Solymar, MD, PhD, ${ }^{1}$ Erika Petervari, MD, PhD, ${ }^{1}$ Marta Balasko, MD, PhD, ${ }^{1}$ Tamas Habon, MD, PhD, ${ }^{6}$ Zoltan Rumbus, MD, ${ }^{1}$ Judit Tenk, MD, PhD, ${ }^{1}$ Ildiko Rostas, MD, PhD, ${ }^{1}$ Jordan Weinberg, MD, FACS ${ }^{7}$ Andrej A. Romanovsky, MD, $\mathrm{PhD},{ }^{7}$ Andras Garami MD, $\mathrm{PhD}^{1 *}$

${ }^{1}$ Institute for Translational Medicine, Medical School, University of Pecs, 12 Szigeti Str., Pecs, H7624, Hungary;

${ }^{2}$ Institute of Bioanalysis, Medical School, University of Pecs, 12 Szigeti Str., Pecs, H7624, Hungary;

${ }^{3}$ Division of Gastroenterology, First Department of Medicine, Medical School, University of Pecs, 13 Ifjusag Str., Pecs, H7624, Hungary;

${ }^{4}$ Momentum Gastroenterology Multidisciplinary Research Group, Hungarian Academy of Sciences - University of Szeged, 6-8 Koranyi Ave., Szeged, H6720, Hungary;

${ }^{5}$ Institute of Surgical Research, University of Szeged, Szeged, Hungary;

${ }^{6}$ Department of Cardiology and Angiology, First Department of Medicine, Medical School, University of Pecs, 13 Ifjusag Str., Pecs, H7624, Hungary;

${ }^{7}$ Trauma Research, St. Joseph's Hospital and Medical Center, 350 West Thomas Road, Phoenix, Arizona 85013, USA

Running title: Cooling index determines the outcome of TBI

Table of Contents title: Cooling reduces mortality in severe traumatic brain injury: a metaanalysis 
Keywords: induced hypothermia, thermoregulation, traumatic brain injury, mortality, meta-analysis (1)

Authors' email addresses: potoneoe@gmail.com; laszlo.poto@aok.pte.hu; hegyi2009@gmail.com; szaboimi@yahoo.com; hartmann.petra@med.u-szeged.hu; margit.solymar@aok.pte.hu; erika.petervari@aok.pte.hu; marta.balasko@aok.pte.hu; habon.tamas@pte.hu; rumbuszoltan@gmail.com; judit.tenk89@gmail.com; ildiko.rostas@gmail.com; jordan.weinberg@dignityhealth.org; andrej.romanovsky@dignityhealth.org; andras.garami@aok.pte.hu

Corresponding author at: Institute for Translational Medicine, Medical School, University of Pecs, 12 Szigeti Str., Pecs, H7624, Hungary. Phone: +36 (72) 536-246; fax: +36 (72) 536247; e-mail: andras.garami@aok.pte.hu 


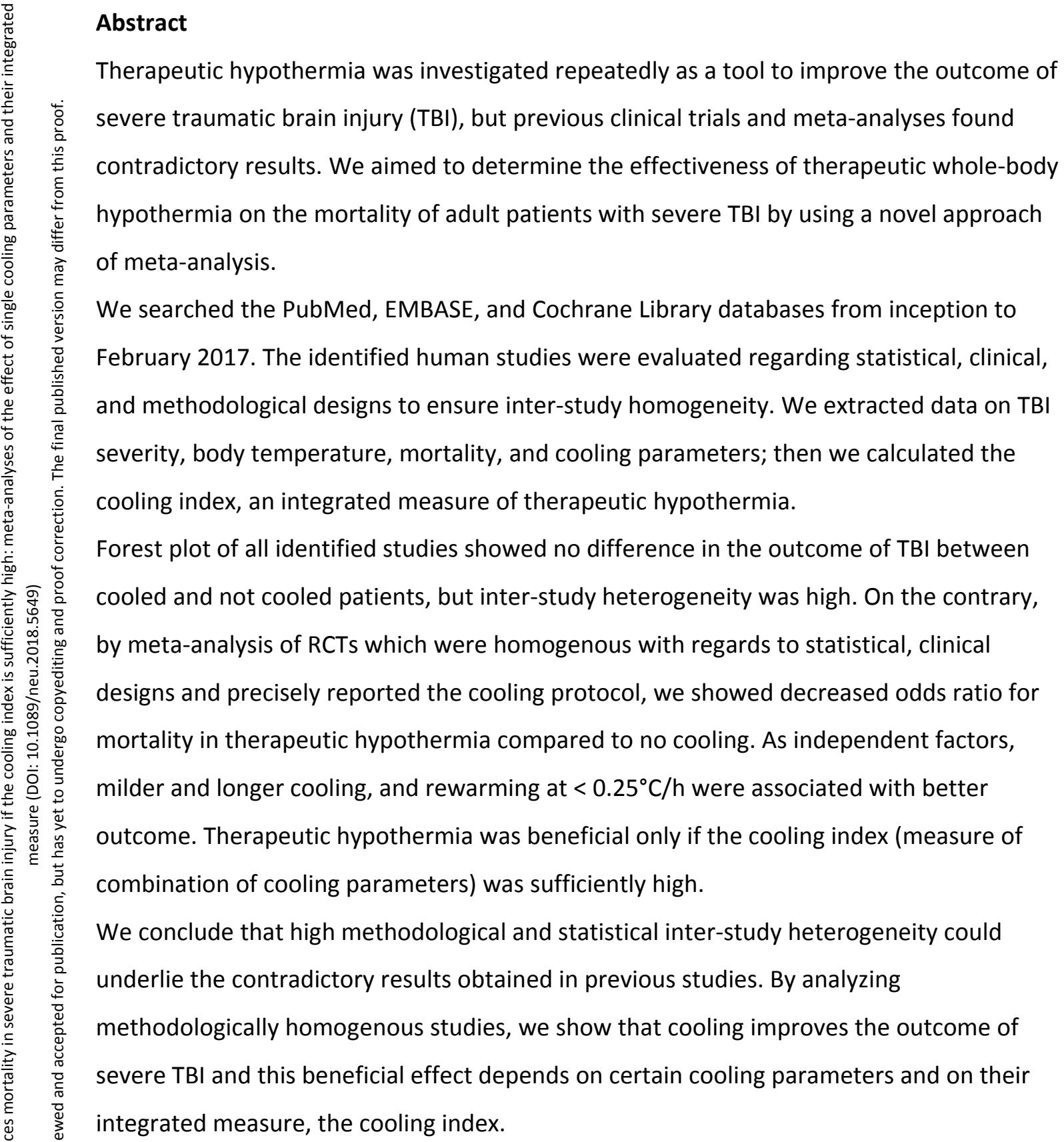




\section{Introduction}

Traumatic brain injury (TBI) is recognized as a significant cause of mortality and morbidity predominantly in the young population. ${ }^{1}$ TBI is estimated to affect 10 million people annually worldwide and by 2020 it can be one of the major causes of death and disability, posing a global health and financial burden for the society. ${ }^{2}$ Among the leading causes of TBI are motor vehicle accidents in both more and less developed countries, most frequently involving young males. ${ }^{2,3}$ Mild head injuries may recover fully without any specific treatment, whereas severe injuries are often rapidly fatal or leave survivors with disabilities. ${ }^{4}$ Severe TBI constitutes a major health and socio-economic problem worldwide. $^{5}$

The pathomechanisms underlying severe TBI are complex and often involve focal as well as diffuse changes. ${ }^{6}$ Focal lesions include contusional damages of the brain parenchyma, most commonly in the frontal and temporal lobes, as well as disruptions in vasculature, resulting in intracerebral and extracerebral heamatomas. ${ }^{5,6}$ In a typical case like the one presented in Table S1, focal lesions are diagnosed with routine imaging techniques, such as computed tomography (see Fig. S1). The primary head injury can initiate a number of pathophysiological processes which will determine the extent and the duration of the damage. These mechanisms involve ischemia, swelling (edema), neurotransmitter release (excitotoxicity), formation of free radicals, ionic flux-mediated damage, metabolic and mitochondrial dysfunction, and neuroinflammatory responses. ${ }^{4-6}$

Many of the pathological mechanisms associated with TBI are temperaturesensitive, ${ }^{7}$ suggesting that at a lower deep body temperature the adverse processes can be decelerated and neuroprotective effects can be achieved. Therapeutic hypothermia has been investigated as a possible neuroprotective strategy to attenuate the harmful effects of severe TBI. In animal models of TBI, beneficial effects of therapeutic hypothermia have been shown repeatedly, ${ }^{8-11}$ but clinical studies provided contradictory results. The first report of the use of hypothermia in TBI was in $1943,{ }^{12}$ while randomized controlled studies appeared only at the end of the 1990s. ${ }^{13}$ Over the last 25 years, numerous clinical trials have been conducted to assess the effects of induced hypothermia in severe TBI. ${ }^{13-31}$ Cooling of patients with severe TBI improved the outcome in several of these studies, ${ }^{14,17}$, 
$21,23,25,26,29-32$ while other trials suggested weak or no evidence for the use of therapeutic hypothermia following TBI. ${ }^{16,20,27,33-35}$ It has to be noted that the study design (e.g., randomization), inclusion criteria of patients, and the applied cooling protocol varied substantially among the trials, which differences could have contributed to the contradictory findings in the human studies.

As attempts to ultimately answer the question of whether therapeutic hypothermia improves the outcome of TBI, several meta-analyses have also been performed. ${ }^{36-42}$ However, the different analyses provided contradictory results. While, about half of them showed that therapeutic hypothermia might be effective in the treatment of TBI and could reduce mortality, ${ }^{36,38,39,41}$ the other half indicated that it did not decrease the mortality rate. $^{37,40,42}$ It can be assumed that the high inter-study variability in the statistical and clinical designs of the trials, which were included in some of the meta-analyses and the different study selection protocols were responsible for the contradictory results. Indeed, high inter-study heterogeneity was reported in all of the performed meta-analyses so far. $^{36-42}$

In the present study, we used a novel approach to determine the efficacy of therapeutic hypothermia in TBI. In our meta-analysis, we carefully evaluated all studies identified by literature search based on statistical design, patient inclusion criteria, and the applied cooling protocol, thereby we identified studies which were homogenously designed from three aspects: statistically (randomization), clinically (whole-body cooling versus no temperature management of patients with severe TBI), and methodologically (cooling protocols precisely reported). Then, we conducted meta-analyses of these studies to evaluate the effects of therapeutic hypothermia as well as that of the individual parameters of the cooling protocol on the mortality rate of patients with severe TBI. We introduced the cooling index, an integrated measure of therapeutic hypothermia calculated from three different cooling parameters, and studied its relation to mortality in severe TBI.

\section{Methods}

Our meta-analysis was conducted in accordance with the guidelines of the Preferred Reporting Items for Systematic Reviews and Meta-Analysis Protocols (Table 
S2). ${ }^{43}$ The analysis was based on the Participants, Intervention, Comparison, Outcome (PICO) model: in severe TBI population, we aimed to assess the effect of therapeutic whole-body hypothermia compared to no cooling on the mortality ratio. This metaanalysis has been registered with PROSPERO International Prospective Register of Systematic Reviews (CRD42017056535).

\section{Literature Search}

A systematic search of the PubMed, EMBASE, and Cochrane Library databases was performed from inception to February 2017 with using the following Medical Subject Headings and search terms: ("hypothermia" OR "cooling") AND ("traumatic brain injury" OR "TBI") AND ("mortality" OR "death" OR "survival"). Then, the "human" filter was selected. We restricted our search to original studies published in English without time period limitations. We included journal articles of the following study types: clinical study, clinical trial, comparative study, controlled clinical trial, controlled study, multicenter study, observational study, and randomized controlled trial.

The search for the articles was conducted separately by two authors (EO and AG), who also assessed study eligibility, and extracted data from the selected studies independently. Disagreements were resolved by consensus with the help of a third author $(Z R)$.

\section{Data Extraction}

Only those studies were included in the meta-analyses, in which the effect of therapeutic hypothermia was compared with no cooling interventions on the mortality ratio of adult patients with severe TBI. Nineteen $\mathrm{RCTs}^{13,14,16,18,20-31,44-46}$ and eight $\operatorname{articles}^{15,17,19,34,47-50}$ of other study types were eligible for meta-analysis. The relevant data were extracted from these studies by two investigators (EO and AG) independently into Microsoft Excel software (Microsoft Corporation, Redmond, WA, USA). The following information was collected from each of the selected articles: authors' names and date of publication, study type and randomization, characteristics of patient population [e.g., mean age, sample size, intracranial pressure (ICP), and Glasgow coma score (GCS) at admission], methods of whole-body cooling (target temperature, duration of hypothermia, 
and rate of rewarming), interventions in the no cooling group, and mortality rates in the study groups.

\section{Data evaluation protocols}

The collected data were evaluated based on a statistical and a biomedical approach. Statistically, we assessed the randomization of the collected studies based on the authors' statements, Jadad analysis, and detailed evaluation of the randomization protocol described in the study (see Quality assessment). In the biomedical evaluation, we narrowed the list of eligible studies to those that dealt with the effects of therapeutic whole-body hypothermia compared with no temperature management, therefore, we excluded those articles, in which selective brain cooling, ${ }^{44,46,51}$ or fever control with antipyretics $^{34,47,48}$ was used, or when patients with spontaneous hypothermia were involved in the study. ${ }^{49,52}$ Eligible studies resulting from the statistical or the biomedical refinement or both were compared with the random effect model of meta-analysis for odds ratio (OR) as effect size. To assess which parameters of the cooling methods have the biggest impact on the outcome of severe TBI, the studies were divided into subgroups based on target cooling temperature, cooling duration, and speed of rewarming. Target cooling temperatures were classified a priori as "moderate" $\left(32-33^{\circ} \mathrm{C}\right)^{53}$ and "mild" (33$\left.35^{\circ} \mathrm{C}\right) .{ }^{29,53}$ Cooling duration was divided into short (24-48h) and long ( $>48 \mathrm{~h}$ ) subgroups..$^{54}$ According to recent recommendations about the use of very slow $\left(0.1-0.2^{\circ} \mathrm{C} / \mathrm{h}\right)$ rewarming rates in patients with severe $\mathrm{TBI}^{55,56}$ the speed of rewarming was divided into either of 2 subgroups: $0.25-1^{\circ} \mathrm{C} / \mathrm{h}$ and less than $0.25^{\circ} \mathrm{C} / \mathrm{h}$, also including passive. Rewarming was determined passive if the cooling process ensued without induction of any cooling or rewarming device within the next 18-24 hours. ${ }^{57,58}$ For quantification purposes, the speed of passive rewarming was considered to equal $0.06^{\circ} \mathrm{C} / \mathrm{h} .{ }^{57,58}$

In addition to analyzing the effect of each cooling parameter individually, the influence of the used combinations of the three parameters together was also assessed on the outcome of severe TBI. When all three parameters, i.e., target cooling temperature, cooling duration, and speed of rewarming, were reported in the same study, we calculated the integrated measure of cooling and named it as the cooling index. The cooling index 
represents the area between the body temperature curve of cooled patients and a hypothetical horizontal line corresponding to a normal body temperature of $36.5^{\circ} \mathrm{C} \mathrm{(Fig.}$ S2). The following formula was used: "cooling index" $=\Delta T \times t+(\Delta T \times \Delta T / R) / 2$, where " $\Delta T$ " is the magnitude of hypothermia, i.e., the difference between normal $\left(36.5^{\circ} \mathrm{C}\right)$ and target cooling temperatures expressed in ${ }^{\circ} \mathrm{C}$; " $\mathrm{t}$ " is duration of the maintenance of hypothermia in hours; and " $\mathrm{R}$ " is the rate of rewarming $\left({ }^{\circ} \mathrm{C} / \mathrm{h}\right)$; see also Fig. S2A. The impact of the rewarming rate was incorporated in the cooling index as the area of the triangle, which represents the change in body temperature during the rewarming phase. It has to be noted that due to the relatively narrow range $\left(0.06-1^{\circ} \mathrm{C} / \mathrm{h}\right)$ of the rewarming rates used in the analyzed studies, this area had the smallest contribution to the final value of the cooling index, while depth and duration of the cooling were more dominant contributors. The cooling index corresponds with the integrated measure of the magnitude and duration of therapeutic hypothermia. For example, a similarly high cooling index can result from short and deep cooling with rewarming at $0.25^{\circ} \mathrm{C} / \mathrm{h}$ (Fig. S2B), as well as from longer, but milder cooling with slower, passive rewarming (Fig. S2A). A moderate cooling index can result from mild and short cooling followed by slow rewarming at $\sim 0.08^{\circ} \mathrm{C} / \mathrm{h}$ (Fig. S2C), while cooling index is low if cooling duration is brief and rewarming is faster $\left(1^{\circ} \mathrm{C} / \mathrm{h}\right)$ even if target cooling temperature is very low (Fig. S2D). For meta-analysis, the included studies were evenly distributed $(N=4)$ into subgroups with low $\left(<160^{\circ} \mathrm{C} \times \mathrm{h}\right)$, moderate (160$\left.200^{\circ} \mathrm{C} \times \mathrm{h}\right)$, and high $\left(>200^{\circ} \mathrm{C} \times \mathrm{h}\right)$ cooling index. Examples for the assessment of the cooling index in each of the three subgroups are presented in Figure S2.

In five of the analyzed studies, ${ }^{14,25,26,29,31}$ the cooling protocol was changed depending from the ICP. Thus, we also compared whether the outcome of TBI differed between the group of studies which reported adjustments in the cooling protocol based on ICP and the group of studies which did not.

\section{Quality assessment}

To evaluate the quality of the included trials, two independent reviewers (EO and ZR) assessed the bias of the included studies according to the Cochrane Handbook. ${ }^{59}$ The methodology described for random sequence generation, allocation concealment, blinding 
of participants and personnel, blinding of outcome assessment, completeness of outcome data, and selective outcome reporting was assessed during the analysis. Due to the nature of the studies eligible for our meta-analyses, the blinding method could not be assessed. The Jadad score, a five-point quality scale was used also to analyze the quality of the articles. ${ }^{60}$ Furthermore, an additional three-step evaluation of the randomization used in each study was performed, which was more relevant for such studies included in our meta-analysis. The first two questions of this evaluation were similar to those of the Jadad score, viz., whether the use of randomization was stated and whether the randomization procedure was appropriate and reported in the study. In the third step, the level of randomization was determined as good, if the use of randomization, and its exact protocol was reported in the study. If the use of randomization was stated, but the exact method was not described, the randomization level was assessed as medium, while in cases when the authors did not mention randomization, the level of randomization was considered low. This evaluation was necessary, because there were several studies in which the use of randomization was stated, but the exact method was not described, ${ }^{21,23,25,27-31}$ which leaves the statement open for questions.

\section{Statistical Analysis}

The statistical analysis was performed according to the standard methods of metaanalysis. The primary effectiveness outcome was all-cause mortality. OR with $95 \%$ confidence intervals $(\mathrm{Cl})$ for mortality in the adult patients with severe TBI were calculated in a random-effects model of meta-analysis. Summary effect estimates were stratified by study design and the between-groups effects were assessed.

Publication bias was assessed with funnel plots by using the Duval and Tweedie trim and fill method ${ }^{61}$ and the Egger's test (Egger's test values of less than 0.1 were considered as indicators of significant small-study effect) (see Supplementary material). Between-study heterogeneity was tested with $Q$ homogeneity test ( $p$ values of less than 0.05 were considered as indicators of significant heterogeneity) and with $\mathrm{I}^{2}$ statistical test, where $\mathrm{I}^{2}$ is the proportion of total variation attributable to between-study variability (an $\mathrm{I}^{2}$ value of more than 50 was considered as indicating considerable heterogeneity). Results of 
the meta-analyses are depicted as forest plots. All analyses were performed using the Comprehensive Meta-Analysis software (version 3.3; Biostat, Inc., Engelwood, MJ, USA).

\section{Results}

Study selection

The flow chart of the study selection is presented in Figure 1. Until February 23, 2017 the literature search identified altogether 709 studies from the PubMed, EMBASE, and Cochrane databases. After enabling filters for human studies and English language and using additional filters (study types) 321 studies remained, which were screened for title and abstract for inclusion criteria. 273 articles were excluded because of insufficient data reporting or because children were studied. 48 studies were included in qualitative synthesis. A further 21 articles were excluded due to the lack of mortality data. 27 studies were included and pooled for quantitative synthesis.

When we compared the effects of therapeutic hypothermia with no cooling by including all 27 identified studies in the meta-analysis (Fig. S3), we did not find a significant difference in the OR for mortality between the groups. Importantly, the included studies were methodologically quite heterogeneous with regards to both statistical and clinical designs $\left(Q=167, p<0.001 ; I^{2}=84\right)$.

As a statistical approach to reduce heterogeneity, we analyzed separately those nineteen studies which could be considered as RCTs (Fig. S4). Therapeutic hypothermia tended to improve the outcome in patients with severe TBI, but the difference did not reach the level of significance $(O R=0.782 ; p=0.075)$. However, between-study heterogeneity was still reasonably high as indicated by the nearly significant result of the $Q$ homogeneity test $(p=0.053)$. Based on detailed quality assessment of the randomization protocols in the studies, the level of randomization was assessed as good in 3 studies, medium in 9 studies, and low in 2 studies (Table S3). The remaining 5 RCTs were not included in this assessment, as they did not pass the criteria set for homogenous clinical and methodological designs (see below). The use of therapeutic hypothermia significantly decreased the risk of mortality in the subgroup of medium randomization level $(O R=$ 0.676; $p=0.041$ ), while no significant difference was found between cooling versus no 
cooling in the other two subgroups (Fig. S5). When the good and medium subgroups were merged, their pooled OR remained significantly lower than 1 ( $O R=0.66, p=0.003)$, which indicated better outcome in therapeutic hypothermia, but clinically, the inter-study heterogeneity was still considerably high.

We evaluated the studies based on clinical and methodological designs. Our goal was to study the effect of therapeutic hypothermia applied to the whole body of patients with severe $\mathrm{TBI}$, but without spontaneous hypothermia and without temperature control. Therefore, 3 trials using selective brain cooling, ${ }^{44,46,51} 2$ articles including cases of spontaneous hypothermia, ${ }^{49,52}$ and 3 studies applying fever control ${ }^{34,47,48}$ had to be excluded from the analysis. Further 4 studies could not be included in the final analyses, because the applied cooling methods were not reported in sufficient details. ${ }^{15,18,19,22}$ In one of the trials GCS of the included patients ranged between $3-15,{ }^{16}$ which sample also includes mild (GCS = 13-15) and moderate cases of TBI (GCS =9-12), therefore it also had to be excluded from further analysis (Fig. 1).

As result of the combined (statistical and physiological) evaluation of the studies identified by our literature search, 14 full-text publications (involving 1,786 adult patients with severe TBI; 896 in the therapeutic hypothermia group and 890 in the no cooling group), were included in the next steps of our analysis. The descriptive statistics of the age, GCS, ICP, and injury severity score in the patient populations from these 14 studies are presented in Table 1. These data reported from a big patient population $(N>1,700)$ correspond with the clinical parameters observed in the patient presented in Table S1. The publication years of the studies ranged from 1993 to 2017. All of them can be considered as randomized trials, in which the exact cooling methods of the whole body (target temperature, cooling duration, and speed of rewarming) are reported, and the effect of therapeutic hypothermia on mortality was compared with patients without temperature management in severe TBI. The homogeneity of the studies was verified by Egger's test, $Q$, and $\mathrm{I}^{2}$ statistics, which showed no significant difference in inter-study variability (Egger's $p$ $\left.=0.509 ; \mathrm{Q}=17, \mathrm{p}=0.224 ; \mathrm{I}^{2}=21\right)$. Meta-analysis of these studies revealed that therapeutic hypothermia significantly improved the outcome of severe TBI $(O R=0.675 ; p=$ 0.004) (Fig. 2). 
Next, we studied the different parameters of the cooling protocol viz., target temperature, cooling duration, and speed of rewarming. Based on target cooling temperatures 4 studies used "moderate" (equal or less than $33^{\circ} \mathrm{C}$ ) and 7 studies "mild" $\left(33-35^{\circ} \mathrm{C}\right)$ hypothermia, while in 3 studies the reported target temperature range overlapped between the moderate and mild groups (Fig. 3). We found that the use of mild therapeutic hypothermia considerably improved the outcome (decreased the risk of death) as compared with no cooling ( $O R=0.627 ; p=0.050)$. No significant differences were found in the moderate hypothermia and the overlapping target temperature groups (Fig. 3). With regards to cooling duration, in 9 studies short (24-48h) hypothermia was used, while in 5 studies cooling was longer than 48 hours (Fig. 4). The effect of long-term hypothermia was beneficial on the mortality rate of patients with severe TBI compared to patients with no temperature management $(O R=0.534 ; p<0.001)$, while in case of shortterm hypothermia the effect was not significant (Fig. 4). Based on the speed of rewarming, the studies were divided into subgroups using rewarming rates of either $0.25-1^{\circ} \mathrm{C} / \mathrm{h}$ or less than $0.25^{\circ} \mathrm{C} / \mathrm{h}$. We found that therapeutic hypothermia improved the outcome of severe $\mathrm{TBI}$ when the rewarming rate was below $0.25^{\circ} \mathrm{C} / \mathrm{h}(\mathrm{OR}=0.58 ; \mathrm{p}=0.014)$, while there was only a tendency for the better outcome when rewarming rate was $\geq 0.25^{\circ} \mathrm{C} / \mathrm{h}(\mathrm{OR}=0.74 ; \mathrm{p}$ $=0.085$ ) (Fig. 5). These results suggest that certain parameters of the cooling protocol can be associated with more beneficial effects of therapeutic hypothermia on the mortality of patients with severe TBI, but how the combination of the different parameters together, i.e., the total extent of cooling, contributes to the outcome could not be firmly established.

In our next approach, we studied the integrated effect of the cooling parameters on the outcome of the disease. From the cooling parameters reported in the studies with medium and good level of randomization (Table S3), the cooling index was assessed by considering all three variables, viz., target temperature, cooling duration, and speed of rewarming, in the formula (for details, see Methods and Fig. S2A). The reported parameters and the cooling index derived from these data are shown in Table 1. By calculating the cooling index, we were able to compare the effect of the overall extent of hypothermia among studies which used different cooling parameters in their protocols. The OR (estimated expected average) in the subgroups with low $\left(<160^{\circ} \mathrm{C} \times \mathrm{h}\right)$, moderate 
$\left(160-200^{\circ} \mathrm{C} \times h\right)$, and high $\left(>200^{\circ} \mathrm{C} \times h\right)$ cooling index was $0.831(p=0.535), 0.754(p=$ $0.340)$, and $0.470(p=0.035)$, respectively (Fig. 6). Importantly, the only significant effect for an OR of less than 1, i.e., when cooling was beneficial compared to no cooling, was observed in the subgroup of studies with high cooling index. These results suggest that in addition to the different independent contribution of each cooling parameter, the integrated measure of the magnitude and duration of therapeutic hypothermia (as indicated by the cooling index) can play a decisive role in determining whether the applied cooling protocol will decrease the risk of death in patients with severe TBI.

We also evaluated whether adjustments of the cooling parameters depending from the ICP of the patients impacts the outcome in severe TBI. When we compared the outcome of TBI between the group of studies which adjusted the cooling protocols based on ICP with the group of studies which did not, we found that when ICP was taken into account, the effect of therapeutic hypothermia was beneficial on the mortality rate of patients with severe TBI compared to patients with no temperature management $(O R=$ $0.53 ; p<0.001)$, while the beneficial effect was not significant when the cooling protocol was not changed depending from ICP $(O R=0.85 ; p=0.265)$ (Fig. 7). These results support the necessity of monitoring ICP and adjusting the cooling parameters depending from ICP during therapeutic hypothermia.

\section{Discussion}

In the present study, we show that whole-body cooling decreases the risk of death in patients with severe TBI by conducting meta-analysis of clinical studies, which were homogenous with regards to statistical, clinical, and methodological designs. By analyzing the individual cooling parameters, we reveal that milder and longer cooling and slower rewarming speed than $0.25^{\circ} \mathrm{C} / \mathrm{h}$ are the most important to improve the outcome of severe TBI. We introduce the cooling index to assess the overall extent of cooling, and show that therapeutic hypothermia is beneficial in severe TBI only if the cooling index is sufficiently high.

Our findings are in line with several clinical trials showing a beneficial effect of therapeutic hypothermia on the outcome of severe TBI, ${ }^{13,14,17,21,23,25,26, ~ 29-31 ~}$ whereas they 
contradict other trials which found no or even adverse effect of whole-body cooling in TBI. $^{20,24,27,28}$ Differences in statistical, clinical, and methodological designs among the studies can be assumed to account for the contradictory results. The highest quality human studies are RCTs, while observational studies and retrospective analyses provide lower level of evidence. Among RCTs the randomization protocol can vary (see Table S3), which results in different levels of statistical bias involved in the trials. Three multi-center clinical trials ${ }^{20,27,28}$ found either no change or worse mortality rates in the cooled groups of patients with TBI, whereas all of the single-center studies ${ }^{13}, 14,17,21,23,25,26,29-31$ showed that therapeutic hypothermia was associated with a lower mortality rate. Differences between results from single-center versus multi-center trials have been observed earlier with regards to therapeutic hypothermia. ${ }^{62}$ Large multi-center trials are usually considered as higher quality studies than single-center trials mostly when pharmacological treatments are investigated, however, when precise execution of the studied intervention is crucial as in the case of therapeutic hypothermia, then the different protocols used in different centers can lead to heterogeneous results, which can mask the differences between the treated and control groups. The study type and randomization level should be taken into account when the findings of a study are evaluated and, especially, when several studies are compared with meta-analysis.

At least in some cases the clinical design of the studies could clearly contribute to mask the effects of therapeutic hypothermia on the outcome. In the study by Andrews et al. ${ }^{16}$ an adverse effect of therapeutic hypothermia on the outcome of TBI was found, however, patients with GCS of 3-15 were included in the trial and subgroup analysis for the different severities of TBI was not performed. Furthermore, it can be assumed that the deleterious effects of cooling on the outcome could be attributable to the different conventional treatments, which were not controlled for between groups. ${ }^{63}$ Clifton et al. ${ }^{30}$ could not confirm the efficacy of therapeutic hypothermia in $\mathrm{TBI}$, which contradicted the results of an earlier phase 2 trial. ${ }^{27}$ However, patients with spontaneous hypothermia were also included in the study, ${ }^{30}$ which could have influenced the results. As opposed to therapeutic hypothermia when deep body temperature decreases due to forced cooling, spontaneous hypothermia is regarded as a regulated, adaptive mechanism in response to 
severe forms of a disease (e.g., systemic inflammation), ${ }^{64}$ and it is often associated with worse outcome. ${ }^{65}$ In some studies the authors used fever control, ${ }^{34,47,48}$ which could also influence the results. Most of the antipyretics (e.g., NSAIDs) do not only reduce fever, but also exert anti-inflammatory and other effects. It has been shown that unlike the use of antipyretics, fever was not associated with mortality in systemic inflammation, ${ }^{66}$ suggesting different biological and clinical implications of fever and antipyretics. ${ }^{66}$ Since inflammatory processes are also involved in the pathomechanism of severe $\mathrm{TBI},{ }^{4-6}$ the use of antipyretics in the control (no cooling) group could change the outcome of the disease.

Methodologically, studies using selective brain cooling ${ }^{44,46,51}$ should be distinguished from those applying whole-body hypothermia, because selective brain cooling is occasionally invasive, and if maintained for several hours, it may induce systemic hypothermia. ${ }^{67}$ A critical appraisal of published clinical studies showed that the methods of therapeutic hypothermia were heterogeneous in terms of timing, depth, duration, and rewarming rate. ${ }^{68}$ The impact of the different cooling methods on the outcome can be reduced if exclusively those studies are compared, in which the cooling parameters are precisely reported, and the role of the parameters is also analyzed.

Previous meta-analyses of the available data from the clinical trials lead to contradictory results regarding the efficacy of therapeutic hypothermia in TBI. ${ }^{36-42}$ It can be assumed that the substantial heterogeneity among the trials included in these metaanalyses could be a crucial factor, which influenced the outcome of the analysis. By using meta-analysis, weighting of the included results can be based only on the deviation reported in a trial. The more uncertain data (greater variability, smaller sample) are taken into account with a lesser weight, but the selection of the studies cannot be accounted for. The novel approach in our meta-analysis is that we extended the conventionally used protocols for study selection by detailed evaluation of the statistical, clinical, and methodological design of the studies. As a result, we identified a group of studies which were homogenous with regard to all three evaluated aspects of the design. By analyzing the results reported in these studies, we found that therapeutic hypothermia improves the outcome of severe TBI and its beneficial effect can be associated with certain cooling parameters (milder and longer cooling, and slower rewarming than $0.25^{\circ} \mathrm{C} / \mathrm{h}$ ). Our results 
about the importance of slow rewarming are well in agreement with data obtained from experimental animals showing that hypothermia followed by slow rewarming provides maximal neuroprotective effect, ${ }^{69,70}$ and further support the current recommendations about the use of very slow $\left(0.1-0.2^{\circ} \mathrm{C} / \mathrm{h}\right)$ rewarming rates in patients with severe TBI. ${ }^{55,56}$ On the contrary, the use of uncontrolled rewarming may potentially offset the benefits of hypothermia, particularly because it may cause rebound intracranial hypertension. ${ }^{13,30}$ Nevertheless, it also has to be noted that since the reported rewarming rates covered only a narrow range, an extended analysis, which would take in account fast, moderate, and slow rewarming of the patients, could not be performed in our study and that the contribution of rewarming to the cooling index was smaller than that of the other two cooling parameters. Importantly, different combinations of the studied parameters can be also advantageous if the total extent of hypothermia (cooling index) is sufficiently high. A high cooling index $\left(\sim 230^{\circ} \mathrm{C} \times \mathrm{h}\right)$, thereby beneficial effect of therapeutic hypothermia could be achieved by different combinations of the cooling parameters, e.g., by short (48h) and deep $\left(32.5^{\circ} \mathrm{C}\right)$ cooling followed by rewarming at a rate of $0.25^{\circ} \mathrm{C} / \mathrm{h},{ }^{30}$ as well as by longer $(72 \mathrm{~h})$ and milder $\left(34^{\circ} \mathrm{C}\right)$ cooling followed by slower $\left(0.06^{\circ} \mathrm{C} / \mathrm{h}\right.$ ) rewarming ${ }^{23}$ (also compare with Fig. S2A and B). By looking at the single cooling parameters used in the two studies, ${ }^{23,30}$ the effect of therapeutic hypothermia on the outcome could seem controversial, as moderate and short cooling ${ }^{30}$ with slower rewarming ${ }^{23}$ were not beneficial, while milder and longer hypothermia ${ }^{23}$ with not so slow rewarming ${ }^{30}$ improved the outcome in severe TBI. However, if the integrated measure of the magnitude and the duration of cooling is considered, viz., the cooling index, then a high extent of hypothermia can be demonstrated in both studies, ${ }^{23,30}$ resulting in a beneficial effect of whole-body cooling on the outcome of severe TBI as seen in the subgroup with high cooling index (OR $=0.47$; Fig. 6). Since the clinical data of the patient presented in Table S1 are similar to the analyzed patient population, it is tempting to speculate that cooling of this patient with the methods specified above could have improved the outcome in his case. Our metaanalysis included data from a total of 1,786 adult patients with severe TBI, but due to the nature of this method, we have studied the reported mean in populations of patients, rather than the association in individual subjects. Therefore, precisely designed clinical trials are needed to confirm our results in clinical settings. The design of such trials should 
include appropriate randomization protocols, targeted population of patients (severe TBI, no pre-existing thermoregulatory disorders, no differences between the study and control groups in medical-surgical treatment), and precise cooling protocols (a combination of parameters with sufficiently high cooling index). By validation of our findings in clinical trials, it would be possible to identify a subpopulation of patients with TBI, in which wellcontrolled therapeutic cooling could improve the outcome.

The addition of further patient characteristics (e.g. ICP, age, comorbidities) and methodological parameters (e.g., initiation time of cooling) to the inclusion criteria of such trial, could help to accurately specify the patient population which can benefit the most from precisely conducted therapeutic hypothermia. Increased ICP can be regarded as both an indicator of the actual brain damage and as a cause of additional pathological changes in severe TBI. ${ }^{55} \mathrm{~A}$ strong body of evidence supports that therapeutic hypothermia is a useful tool to decrease ICP in TBI, however this does not necessarily improve the outcome of the disease. ${ }^{68}$ The contradiction between the management of intracranial hypertension and the lack of improvement in the outcome can be due to inadequate maintenance of the hypothermia-induced lower ICP, because of the applied cooling protocol. Rebound increases of ICP are more common in patients with TBI if the cooling duration is too short and the rate of rewarming is too fast. ${ }^{53}$ To avoid the adverse changes in ICP, five of the analyzed studies reported that the designed cooling protocol was adjusted based on the ICP. ${ }^{14,25,26,29,31}$ Here, we showed that in these studies therapeutic hypothermia significantly improved the outcome in severe TBI compared to those trials which followed the protocol regardless of ICP. $8,13,17,20,23,24,27,28,30$ These results highlight the importance of continuous ICP monitoring during therapeutic hypothermia and warrant for the need of adjustments in the cooling protocol based on ICP. Unfortunately, the data about the deviations from the set protocols were not reported in sufficient details in any of the studies, in order to account for the changes in our calculation of the cooling index. It would also be interesting to study how pharmacological tools can be implemented in the induction of hypothermia in addition to external cooling of the body. Ideal candidates for such drugs could be among the new generation of the antagonists of the transient receptor potential vanilloid-1 channel, which were developed as painkillers, but can cause 
marked hypothermia. ${ }^{71}$ These additional parameters could not be included in the present meta-analysis because of insufficient data availability. Due to the same reason, the upper limit of the cooling index, i.e., above which the harmful effect of hypothermia would dominate over the beneficial effects, could not be determined in our analysis. In the included trials, even from which the highest cooling indices were calculated, cooling of the patients improved the outcome. ${ }^{21,23,29,30}$ It can be expected that the upper safety limit of the cooling index would need to be established separately for the different study populations. Identification of the exact cooling protocol for a specified patient population would be in line with recent paradigms in the treatment of TBI, suggesting the need for targeted management of individuals or subsets of patients to improve the outcome. ${ }^{72,73}$

\section{Acknowledgments}

This research has been supported by the National Research, Development and Innovation Office (grant FK 124483), the New National Excellence Program of the Hungarian Ministry of Human Capacities (UNKP-17-4-III-PTE-33), GINOP STAY ALIVE (grant 2.3.2-15-201600048), and EFOP LIVE LONGER (grant 3.6.2-16-2017-00006).

\section{Author Disclosure Statement}

No competing financial interests exist. 


\section{References}

1. Yokobori, S. and Yokota, H. (2016). Targeted temperature management in traumatic brain injury. J Intensive Care 4, 28.

2. Hyder, A.A., Wunderlich, C.A., Puvanachandra, P., Gururaj, G. and Kobusingye, O.C. (2007). The impact of traumatic brain injuries: a global perspective. NeuroRehabilitation $22,341-353$.

3. Taylor, C.A., Greenspan, A.I., Xu, L. and Kresnow, M.J. (2015). Comparability of national estimates for traumatic brain injury-related medical encounters. J Head Trauma Rehabil 30, 150-159.

4. Finfer, S.R. and Cohen, J. (2001). Severe traumatic brain injury. Resuscitation 48, 77-90.

5. Maas, A.I.R., Stocchetti, N. and Bullock, R. (2008). Moderate and severe traumatic brain injury in adults. Lancet Neurology 7, 728-741.

6. McGinn, M.J. and Povlishock, J.T. (2016). Pathophysiology of traumatic brain injury. Neurosurg Clin N Am 27, 397-407.

7. Sahuquillo, J. and Vilalta, A. (2007). Cooling the injured brain: how does moderate hypothermia influence the pathophysiology of traumatic brain injury. Curr Pharm Des 13, 2310-2322.

8. Zhao, W.Y., Chen, S.B., Wang, J.J., Xu, C., Zhao, M.L., Dong, H.J., Liang, H.Q., Li, X.H., Tu, Y., Zhang, S., Chen, C. and Sun, H.T. (2017). Establishment of an ideal time window model in hypothermic-targeted temperature management after traumatic brain injury in rats. Brain Res 1669, 141-149.

9. Bramlett, H.M. and Dietrich, W.D. (2012). The effects of posttraumatic hypothermia on diffuse axonal injury following parasagittal fluid percussion brain injury in rats. Ther Hypothermia Temp Manag 2, 14-23.

10. Feng, J.F., Zhang, K.M., Jiang, J.Y., Gao, G.Y., Fu, X.A. and Liang, Y.M. (2010). Effect of therapeutic mild hypothermia on the genomics of the hippocampus after moderate traumatic brain injury in rats. Neurosurgery 67, 730-742.

11. Dietrich, W.D., Atkins, C.M. and Bramlett, H.M. (2009). Protection in animal models of brain and spinal cord injury with mild to moderate hypothermia. J Neurotrauma 26, 301312. 
12. Fay, T. (1943). Observations on generalized refrigeration in cases of severe cerebral trauma. Assoc Res Nerv Ment Dis Proc 611-619.

13. Marion, D.W., Penrod, L.E., Kelsey, S.F., Obrist, W.D., Kochanek, P.M., Palmer, A.M., Wisniewski, S.R. and DeKosky, S.T. (1997). Treatment of traumatic brain injury with moderate hypothermia. N Engl J Med 336, 540-546.

14. Tang, C.H., Bao, Y., Qi, M., Zhou, L.Z., Liu, F., Mao, J., Lei, Q.M., Qi, S.T. and Qiu, B.H. (2017). Mild induced hypothermia for patients with severe traumatic brain injury after decompressive craniectomy. J Crit Care 39, 267-270.

15. Balvers, K., Van der Horst, M., Graumans, M., Boer, C., Binnekade, J.M., Goslings, J.C. and Juffermans, N.P. (2016). Hypothermia as a predictor for mortality in trauma patients at admittance to the Intensive Care Unit. J Emerg Trauma Shock 9, 97-102.

16. Andrews, P.J.D., Sinclair, H.L., Rodriguez, A., Harris, B.A., Battison, C.G., Rhodes, J.K.J., Murray, G.D. and Eurotherm Trial, C. (2015). Hypothermia for intracranial hypertension after traumatic brain injury. N Engl J Med 373, 2403-2412.

17. Liu, Y.H., Shang, Z.D., Chen, C., Lu, N., Liu, Q.F., Liu, M. and Yan, J. (2015). 'Cool and quiet' therapy for malignant hyperthermia following severe traumatic brain injury: a preliminary clinical approach. Exp Ther Med 9, 464-468.

18. Suehiro, E., Koizumi, H., Kunitsugu, I., Fujisawa, H. and Suzuki, M. (2014). Survey of brain temperature management in patients with traumatic brain injury in the Japan neurotrauma data bank. J Neurotrauma 31, 315-320.

19. Rincon, F., Hunter, K., Schorr, C., Dellinger, R.P. and Zanotti-Cavazzoni, S. (2014). The epidemiology of spontaneous fever and hypothermia on admission of brain injury patients to intensive care units: a multicenter cohort study. J Neurosurg 121, 950-960.

20. Clifton, G.L., Valadka, A., Zygun, D., Coffey, C.S., Drever, P., Fourwinds, S., Janis, L.S., Wilde, E., Taylor, P., Harshman, K., Conley, A., Puccio, A., Levin, H.S., McCauley, S.R., Bucholz, R.D., Smith, K.R., Schmidt, J.H., Scott, J.N., Yonas, H. and Okonkwo, D.O. (2011). Very early hypothermia induction in patients with severe brain injury (the National Acute Brain Injury Study: Hypothermia II): a randomised trial. Lancet Neurology 10, 131-139.

21. Zhao, Q.J., Zhang, X.G. and Wang, L.X. (2011). Mild hypothermia therapy reduces blood glucose and lactate and improves neurologic outcomes in patients with severe traumatic brain injury. J Crit Care 26, 311-315. 
22. Lee, H.C., Chuang, H.C., Cho, D.Y., Cheng, K.F., Lin, P.H. and Chen, C.C. (2010). Applying cerebral hypothermia and brain oxygen monitoring in treating severe traumatic brain injury. World Neurosurg 74, 654-660.

23. Smrcka, M., Vidlák, M., Máca, K., Smrcka, V. and Gál, R. (2005). The influence of mild hypothermia on ICP, CPP and outcome in patients with primary and secondary brain injury. Acta Neurochir Suppl 95, 273-275.

24. Hashiguchi, N., Shiozaki, T., Ogura, H., Tanaka, H., Koh, T., Noborio, M., Fugita, K., Akimau, P., Kuwagata, Y., Shimazu, T. and Sugimoto, H. (2003). Mild hypothermia reduces expression of heat shock protein 60 in leukocytes from severely head-injured patients. J Trauma 55, 1054-1060.

25. Zhi, D.S., Zhang, S. and Lin, X. (2003). Study on therapeutic mechanism and clinical effect of mild hypothermia in patients with severe head injury. Surg Neurol 59, 381-385.

26. Polderman, K.H., Joe, R.T.T., Peerdeman, S.M., Vandertop, W.P. and Girbes, A.R.J. (2002). Effects of therapeutic hypothermia on intracranial pressure and outcome in patients with severe head injury. Intensive Care Med 28, 1563-1573.

27. Clifton, G.L., Miller, E.R., Choi, S.C., Levin, H.S., McCauley, S., Smith, K.R., Muizelaar, J.P., Wagner, F.C., Marion, D.W., Luerssen, T.G., Chesnut, R.M. and Schwartz, M. (2001). Lack of effect of induction of hypothermia after acute brain injury. N Engl J Med 344, 556-563.

28. Shiozaki, T., Hayakata, T., Taneda, M., Nakajima, Y., Hashiguchi, N., Fujimi, S., Nakamori, Y., Tanaka, H., Shimazu, T., Sugimoto, H. and Mild Hypothermia Study Grp, J. (2001). A multicenter prospective randomized controlled trial of the efficacy of mild hypothermia for severely head injured patients with low intracranial pressure. J Neurosurg 94, 50-54.

29. Jiang, J.Y., Yu, M.K. and Zhu, C. (2000). Effect of long-term mild hypothermia therapy in patients with severe traumatic brain injury: 1-year follow-up review of 87 cases. J Neurosurg 93, 546-549.

30. Clifton, G.L., Allen, S., Barrodale, P., Plenger, P., Berry, J., Koch, S., Fletcher, J., Hayes, R.L. and Choi, S.C. (1993). A phase II study of moderate hypothermia in severe brain injury. J Neurotrauma 10, 263-271.

31. Shiozaki, T., Sugimoto, H., Taneda, M., Yoshida, H., Iwai, A., Yoshioka, T. and Sugimoto, T. (1993). Effect of mild hypothermia on uncontrollable intracranial hypertension after severe head-injury. J Neurosurg 79, 363-368. 
32. Marion, D.W. and Regasa, L.E. (2014). Revisiting therapeutic hypothermia for severe traumatic brain injury ... again. Crit Care 18.

33. Lei, J., Gao, G.Y., Mao, Q., Feng, J.F., Wang, L., You, W.D., Jiang, J.Y. and Collaborators, L.T.-T. (2015). Rationale, methodology, and implementation of a nationwide multicenter randomized controlled trial of long-term mild hypothermia for severe traumatic brain injury (the LTH-1 trial). Contemp Clin Trials 40, 9-14.

34. Maekawa, T., Yamashita, S., Nagao, S., Hayashi, N., Ohashi, Y. and Brain-Hypothermia, B.H.S.G. (2015). Prolonged mild therapeutic hypothermia versus fever control with tight hemodynamic monitoring and slow rewarming in patients with severe traumatic brain injury: a randomized controlled trial. J Neurotrauma 32, 422-429.

35. Nichol, A., Gantner, D., Presneill, J., Murray, L., Trapani, T., Bernard, S., Cameron, P., Capellier, G., Forbes, A., McArthur, C., Newby, L., Rashford, S., Rosenfeld, J.V., Smith, T., Stephenson, M., Varma, D., Walker, T., Webb, S. and Cooper, D.J. (2015). Protocol for a multicentre randomised controlled trial of early and sustained prophylactic hypothermia in the management of traumatic brain injury. Crit Care Resusc 17, 92-100.

36. Crompton, E.M., Lubomirova, I., Cotlarciuc, I., Han, T.S., Sharma, S.D. and Sharma, P. (2017). Meta-analysis of therapeutic hypothermia for traumatic brain injury in adult and pediatric patients. Crit Care Med 45, 575-583.

37. Zhu, Y.F., Yin, H.Y., Zhang, R., Ye, X.L. and Wei, J.R. (2016). Therapeutic hypothermia versus normothermia in adult patients with traumatic brain injury: a meta-analysis. Springerplus 5.

38. Li, P.C. and Yang, C.H. (2014). Moderate hypothermia treatment in adult patients with severe traumatic brain injury: a meta-analysis. Brain Injury 28, 1036-1041.

39. Peterson, K., Carson, S. and Carney, N. (2008). Hypothermia treatment for traumatic brain injury: a systematic review and meta-analysis. J Neurotrauma 25, 62-71.

40. Henderson, W.R., Dhingra, V.K., Chittock, D.R., Fenwick, J.C. and Ronco, J.J. (2003). Hypothermia in the management of traumatic brain injury - a systematic review and metaanalysis. Intensive Care Med 29, 1637-1644.

41. Mclntyre, L.A., Fergusson, D.A., Hebert, P.C., Moher, D. and Hutchison, J.S. (2003). Prolonged therapeutic hypothermia after traumatic brain injury in adults - a systematic review. JAMA 289, 2992-2999. 
42. Harris, O.A., Colford, J.M., Good, M.C. and Matz, P.G. (2002). The role of hypothermia in the management of severe brain injury. A meta-analysis. Arch Neurol 59, 1077-1083.

43. Moher, D., Shamseer, L., Clarke, M., Ghersi, D., Liberati, A., Petticrew, M., Shekelle, P. and Stewart, L.A. (2015). Preferred reporting items for systematic review and meta-analysis protocols (PRISMA-P) 2015 statement. Syst Rev 4, 1.

44. Harris, O.A., Muh, C.R., Surles, M.C., Pan, Y., Rozycki, G., Macleod, J. and Easley, K. (2009). Discrete cerebral hypothermia in the management of traumatic brain injury: a randomized controlled trial Clinical article. J Neurosurg 110, 1256-1264.

45. Qiu, W., Zhang, Y., Sheng, H., Zhang, J.M., Wang, W.M., Liu, W.G., Chen, K.Y., Zhou, J.F. and Xu, Z.F. (2007). Effects of therapeutic mild hypothermia on patients with severe traumatic brain injury after craniotomy. J Crit Care 22, 229-235.

46. Liu, W.G., Qiu, W.S., Zhang, Y., Wang, W.M., Lu, F. and Yang, X.F. (2006). Effects of selective brain cooling in patients with severe traumatic brain injury: a preliminary study. J Int Med Res 34, 58-64.

47. Hifumi, T., Kuroda, Y., Kawakita, K., Yamashita, S., Oda, Y., Dohi, K., Maekawa, T. and Brain Hypothermia, B.H.S.G. (2016). Fever control management is preferable to mild therapeutic hypothermia in traumatic brain injury patients with abbreviated injury scale 34: a multi-center, randomized controlled trial. J Neurotrauma 33, 1047-1053.

48. Suehiro, E., Koizumi, H., Fujisawa, H., Fujita, M., Kaneko, T., Oda, Y., Yamashita, S., Tsuruta, R., Maekawa, T. and Suzuki, M. (2015). Diverse effects of hypothermia therapy in patients with severe traumatic brain injury based on the computed tomography classification of the traumatic coma data bank. J Neurotrauma 32, 353-358.

49. Tohme, S., Delhumeau, C., Zuercher, M., Haller, G. and Walder, B. (2014). Prehospital risk factors of mortality and impaired consciousness after severe traumatic brain injury: an epidemiological study. Scand J Trauma Resusc Emerg Med 22.

50. Bukur, M., Hadjibashi, A.A., Ley, E.J., Malinoski, D., Singer, M., Barmparas, G., Margulies, D. and Salim, A. (2012). Impact of prehospital hypothermia on transfusion requirements and outcomes. J Trauma Acute Care Surg 73, 1195-1201.

51. Qiu, W.S., Shen, H., Zhang, Y., Wang, W.M., Liu, W.G., Jiang, Q.Z., Luo, M. and Manou, M. (2006). Noninvasive selective brain cooling by head and neck cooling is protective in severe traumatic brain injury. J Clin Neurosci 13, 995-1000. 
52. Bukur, M., Kurtovic, S., Berry, C., Tanios, M., Ley, E.J. and Salim, A. (2012). Pre-hospital hypothermia is not associated with increased survival after traumatic brain injury. J Surg Res 175, 24-29.

53. Povlishock, J.T. and Wei, E.P. (2009). Posthypothermic rewarming considerations following traumatic brain injury. J Neurotrauma 26, 333-340.

54. Jiang, J.Y., Xu, W., Li, W.P., Gao, G.Y., Bao, Y.H., Liang, Y.M. and Luo, Q.Z. (2006). Effect of long-term mild hypothermia or short-term mild hypothermia on outcome of patients with severe traumatic brain injury. J Cereb Blood Flow Metab 26, 771-776.

55. Polderman, K.H. (2009). Mechanisms of action, physiological effects, and complications of hypothermia. Crit Care Med 37, S186-202.

56. Polderman, K.H. (2015). How to Stay Cool in the Intensive Care Unit? Endovascular Versus Surface Cooling. Circulation 132, 152-157.

57. Steiner, T., Friede, T., Aschoff, A., Schellinger, P.D., Schwab, S. and Hacke, W. (2001). Effect and feasibility of controlled rewarming after moderate hypothermia in stroke patients with malignant infarction of the middle cerebral artery. Stroke 32, 2833-2835.

58. Schwab, S., Schwarz, S., Spranger, M., Keller, E., Bertram, M. and Hacke, W. (1998). Moderate hypothermia in the treatment of patients with severe middle cerebral artery infarction. Stroke 29, 2461-2466.

59. Higgins, J.P.T., Altman, D.G., Gotzsche, P.C., Juni, P., Moher, D., Oxman, A.D., Savovic, J., Schulz, K.F., Weeks, L., Sterne, J.A.C., Cochrane Bias Methods, G. and Cochrane Stat Methods, G. (2011). The Cochrane Collaboration's tool for assessing risk of bias in randomised trials. BMJ 343.

60. Jadad, A.R., Moore, R.A., Carroll, D., Jenkinson, C., Reynolds, D.J.M., Gavaghan, D.J. and McQuay, H.J. (1996). Assessing the quality of reports of randomized clinical trials: is blinding necessary? Controlled Clin Trials 17, 1-12.

61. Duval, S. and Tweedie, R. (2000). Trim and fill: a simple funnel-plot-based method of testing and adjusting for publication bias in meta-analysis. Biometrics 56, 455-463.

62. Marion, D. and Bullock, M.R. (2009). Current and future role of therapeutic hypothermia. J Neurotrauma 26, 455-467.

63. Shaefi, S., Mittel, A.M., Hyam, J.A., Boone, M.D., Chen, C.C. and Kasper, E.M. (2016). Hypothermia for severe traumatic brain injury in adults: recent lessons from randomized 
controlled trials. Surg Neurol Int 7, 103.

64. Fonseca, J.E., Santos, M.J., Canhao, H. and Choy, E. (2009). Interleukin-6 as a key player in systemic inflammation and joint destruction. Autoimmun Rev 8, 538-542.

65. Rumbus, Z., Matics, R., Hegyi, P., Zsiboras, C., Szabo, I., Illes, A., Petervari, E., Balasko, M., Marta, K., Miko, A., Parniczky, A., Tenk, J., Rostas, I., Solymar, M. and Garami, A. (2017). Fever is associated with reduced, hypothermia with increased mortality in septic patients: a meta-analysis of clinical trials. Plos One 12, 15.

66. Lee, B.H., Inui, D., Suh, G.Y., Kim, J.Y., Kwon, J.Y., Park, J., Tada, K., Tanaka, K., letsugu, K., Uehara, K., Dote, K., Tajimi, K., Morita, K., Matsuo, K., Hoshino, K., Hosokawa, K., Lee, K.H., Lee, K.M., Takatori, M., Nishimura, M., Sanui, M., Ito, M., Egi, M., Honda, N., Okayama, N., Shime, N., Tsuruta, R., Nogami, S., Yoon, S.H., Fujitani, S., Koh, S.O., Takeda, S., Saito, S., Hong, S.J., Yamamoto, T., Yokoyama, T., Yamaguchi, T., Nishiyama, T., Igarashi, T., Kakihana, Y., Koh, Y. and Fever Antipyretic Critically, I. (2012). Association of body temperature and antipyretic treatments with mortality of critically ill patients with and without sepsis: multicentered prospective observational study. Crit Care 16.

67. Westermaier, T., Nickl, R., Koehler, S., Fricke, P., Stetter, C., Rueckriegel, S.M. and Ernestus, R.I. (2017). Selective brain cooling after traumatic brain injury: effects of three different cooling methods-case report. J Neurol Surg A Cent Eur Neurosurg 78, 397-402.

68. Polderman, K.H. (2008). Induced hypothermia and fever control for prevention and treatment of neurological injuries. Lancet 371, 1955-1969.

69. Suehiro, E. and Povlishock, J.T. (2001). Exacerbation of traumatically induced axonal injury by rapid posthypothermic rewarming and attenuation of axonal change by cyclosporin A. J Neurosurg 94, 493-498.

70. Suehiro, E., Ueda, Y., Wei, E.P., Kontos, H.A. and Povlishock, J.T. (2003). Posttraumatic hypothermia followed by slow rewarming protects the cerebral microcirculation. J Neurotrauma 20, 381-390.

71. Garami, A., Pakai, E., McDonald, H.A., Reilly, R.M., Gomtsyan, A., Corrigan, J.J., Pinter, E., Zhu, D.X.D., Lehto, S.G., Gavva, N.R., Kym, P.R. and Romanovsky, A.A. (2018). TRPV1 antagonists that cause hypothermia, instead of hyperthermia, in rodents: compounds' pharmacological profiles, in vivo targets, thermoeffectors recruited, and implications for drug development. Acta Physiol (Oxf) (in press). 


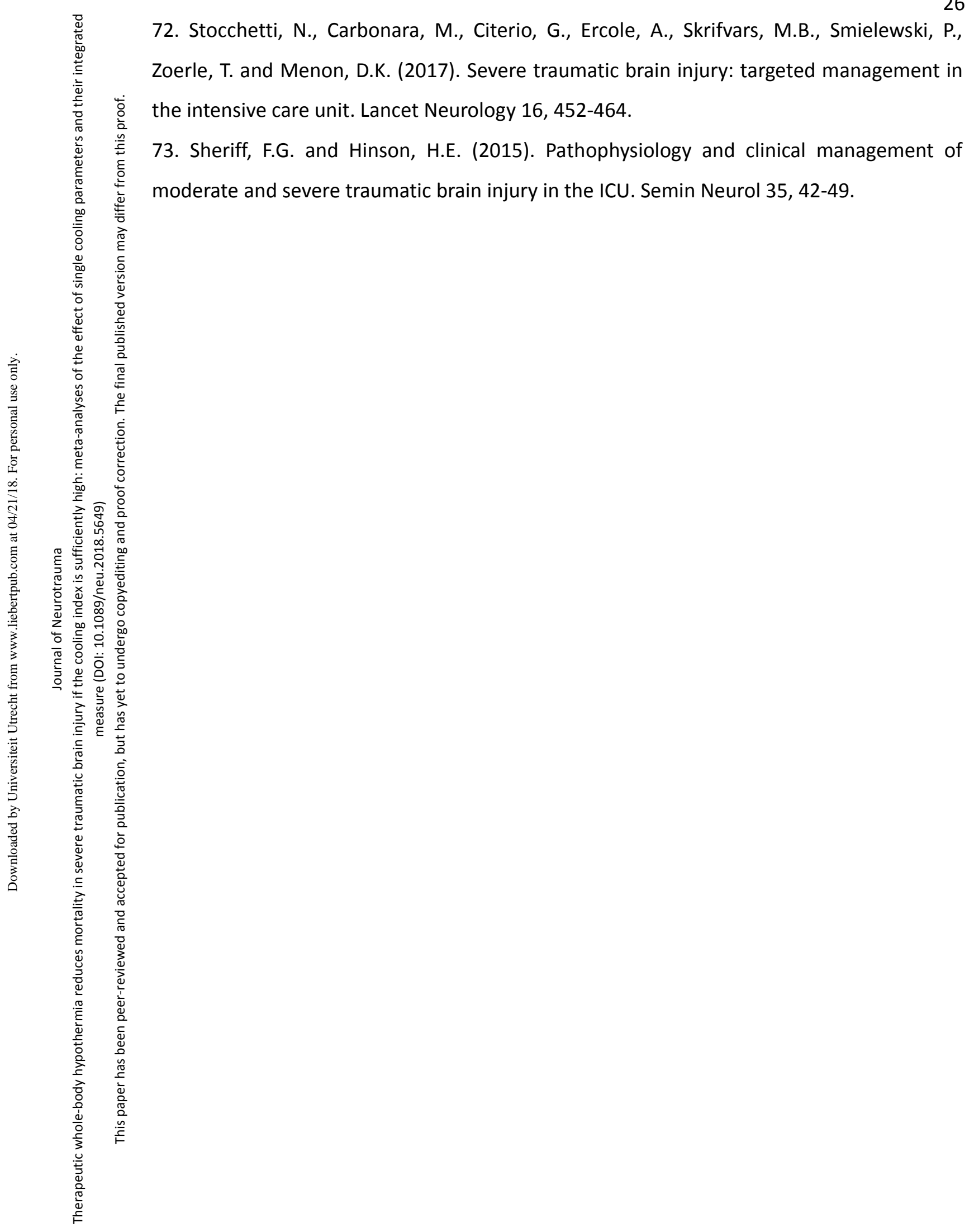




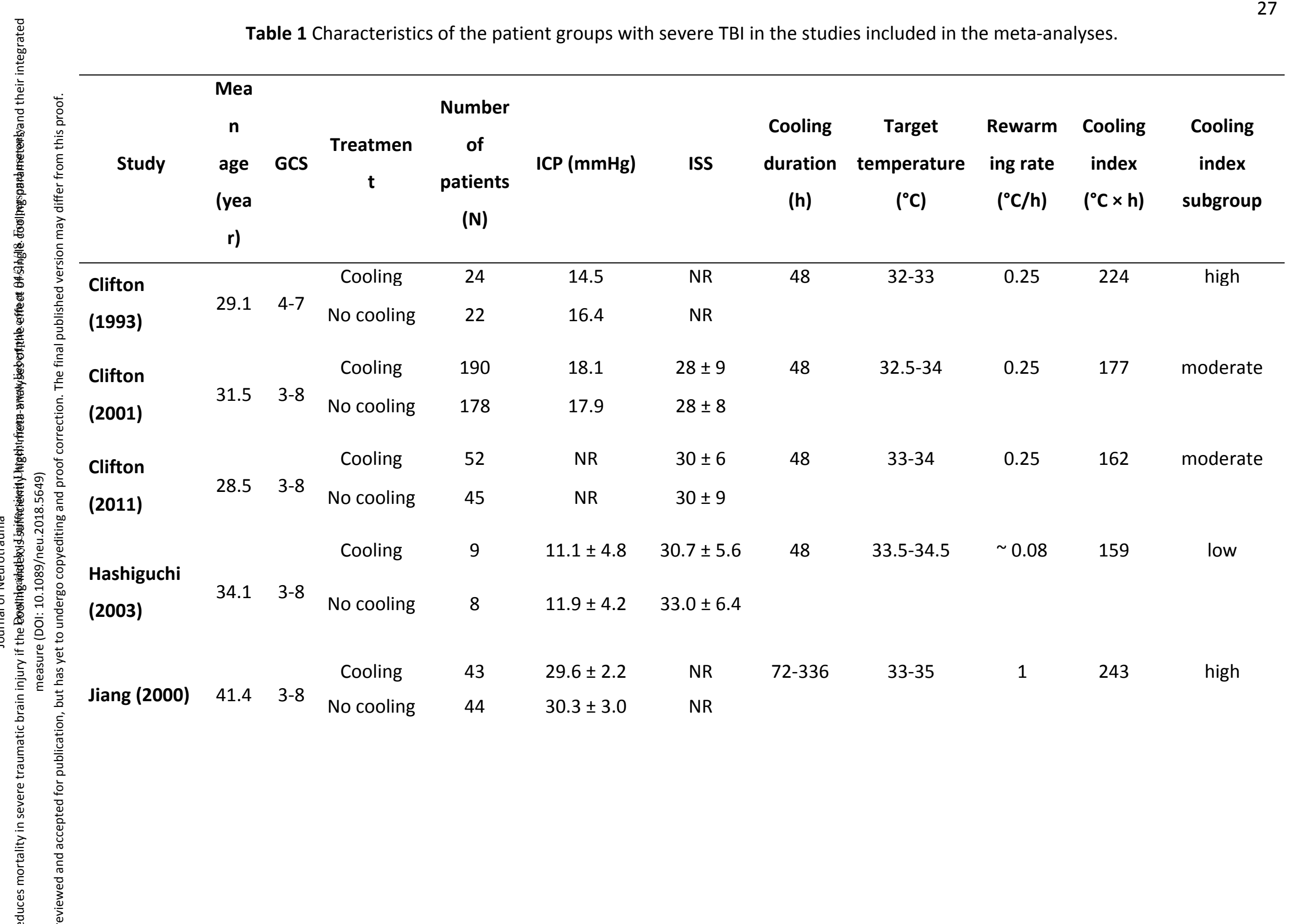




\begin{tabular}{|c|c|c|c|c|c|c|c|c|c|c|c|c|}
\hline & Liu (2015) & NR & $3-8$ & Cooling & 110 & $27.5 \pm 16.9$ & NR & $72-288$ & $35-36$ & $<0.25$ & - & - \\
\hline & (10 $(2000)$ & IVIn & J-0 & No cooling & 110 & $26.8 \pm 17.5$ & NR & & & & & \\
\hline \multirow{5}{*}{\multicolumn{2}{|c|}{ 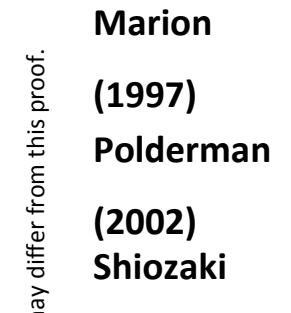 }} & \multirow{2}{*}{33.5} & \multirow{2}{*}{$3-7$} & Cooling & 40 & 15.4 & NR & 24 & $32-33$ & 1 & 104 & low \\
\hline & & & & No cooling & 42 & 19.7 & NR & & & & & \\
\hline & & \multirow{2}{*}{36.7} & \multirow{2}{*}{$3-8$} & Cooling & 64 & $37.0 \pm 20.0$ & NR & 24 & 32 & 0.08 & - & - \\
\hline & & & & No cooling & 72 & $<20.0$ & NR & & & & & \\
\hline & & \multirow{2}{*}{35.4} & \multirow{2}{*}{$<8$} & Cooling & 16 & $35.4 \pm 12.0$ & NR & 48 & $33.5-34.5$ & passive & 172 & moderate \\
\hline$\sum_{\Sigma}^{\pi}$ & (1993) & & & No cooling & 17 & $36.9 \pm 12.1$ & NR & & & & & \\
\hline 产 & Shiozaki & \multirow{2}{*}{38.5} & \multirow{2}{*}{$3-8$} & Cooling & 45 & NR & NR & 48 & $33.5-34.5$ & $\sim 0.08$ & 159 & low \\
\hline 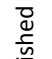 & (2001) & & & No cooling & 46 & NR & NR & & & & & \\
\hline$\frac{\bar{a}}{2}$ & Smrcka & \multirow{2}{*}{41.0} & \multirow{2}{*}{$3-8$} & Cooling & 35 & NR & $11.8 \pm 5$ & 72 & 34 & passive & 232 & high \\
\hline 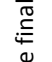 & (2005) & & & No cooling & 37 & NR & $17.6 \pm 7$ & & & & & \\
\hline $\begin{array}{l}\bar{F} \\
\dot{c}\end{array}$ & \multirow[t]{2}{*}{ Tang (2017) } & \multirow[t]{2}{*}{41.1} & \multirow[t]{2}{*}{$3-8$} & Cooling & 30 & NR & $\mathrm{NR}$ & 48 & $32-35$ & 0.25 & 162 & moderate \\
\hline & & & & No cooling & 30 & NR & NR & & & & & \\
\hline 产 & \multirow[t]{2}{*}{ Zhao (2011) } & \multirow[t]{2}{*}{37.2} & \multirow[t]{2}{*}{$3-8$} & Cooling & 40 & $15.9 \pm 4.3$ & NR & 72 & $32.5-33$ & passive & 387 & high \\
\hline ¿ँ & & & & No cooling & 41 & $17.1 \pm 5.0$ & NR & & & & & \\
\hline & \multirow{2}{*}{ Zhi (2003) } & \multirow{2}{*}{42.5} & \multirow{2}{*}{$3-8$} & Cooling & 198 & $26.9 \pm 4.6$ & NR & $24-168$ & $32-35$ & 0.25 & 138 & low \\
\hline & & & & No cooling & 198 & $26.6 \pm 4.9$ & NR & & & & & \\
\hline
\end{tabular}

-, not applicable; GCS, Glasgow coma score; ICP, intracranial pressure; ISS, injury severity score; NR, not reported. 


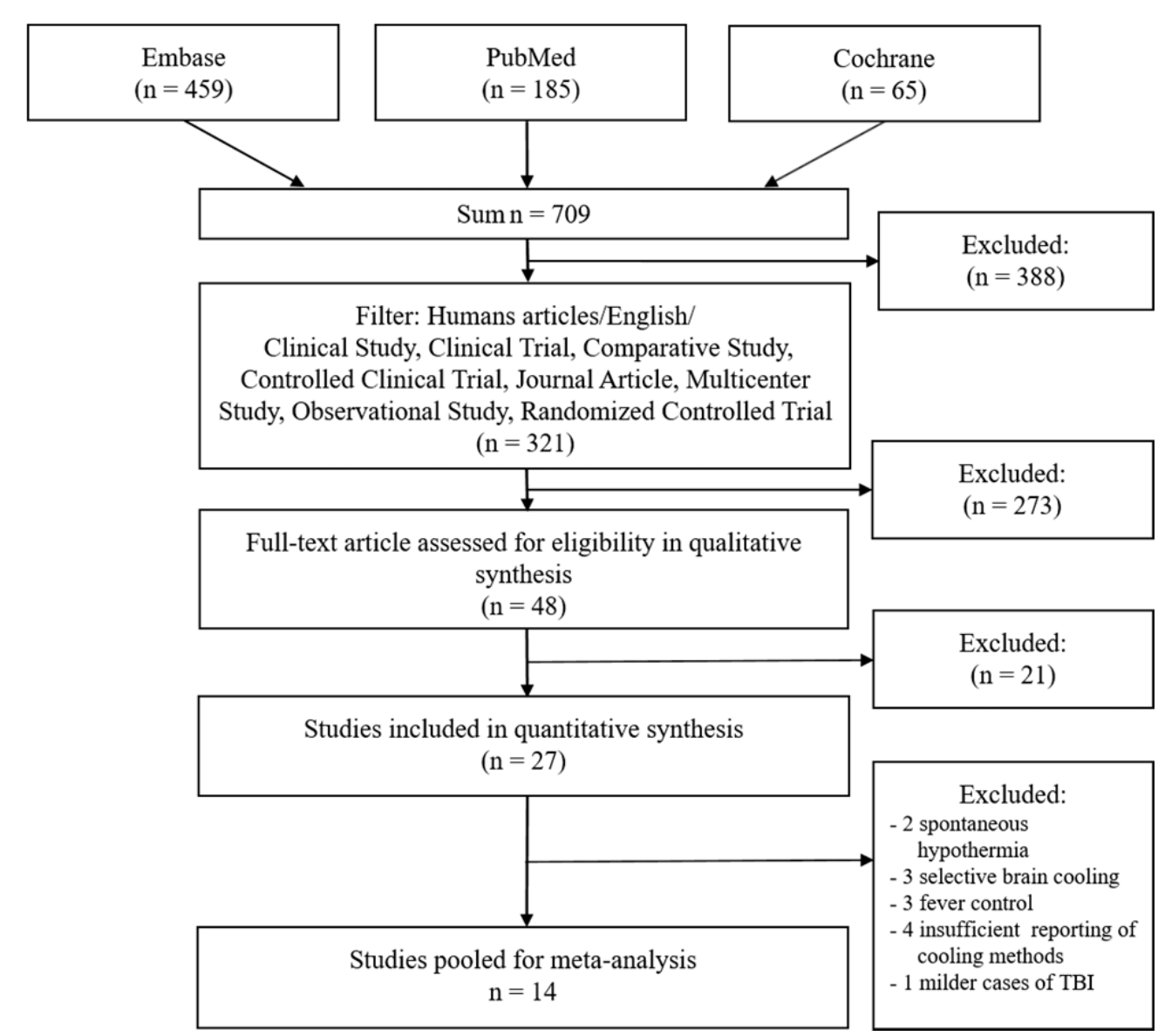

Figure 1 Flow chart of study selection and inclusion. 


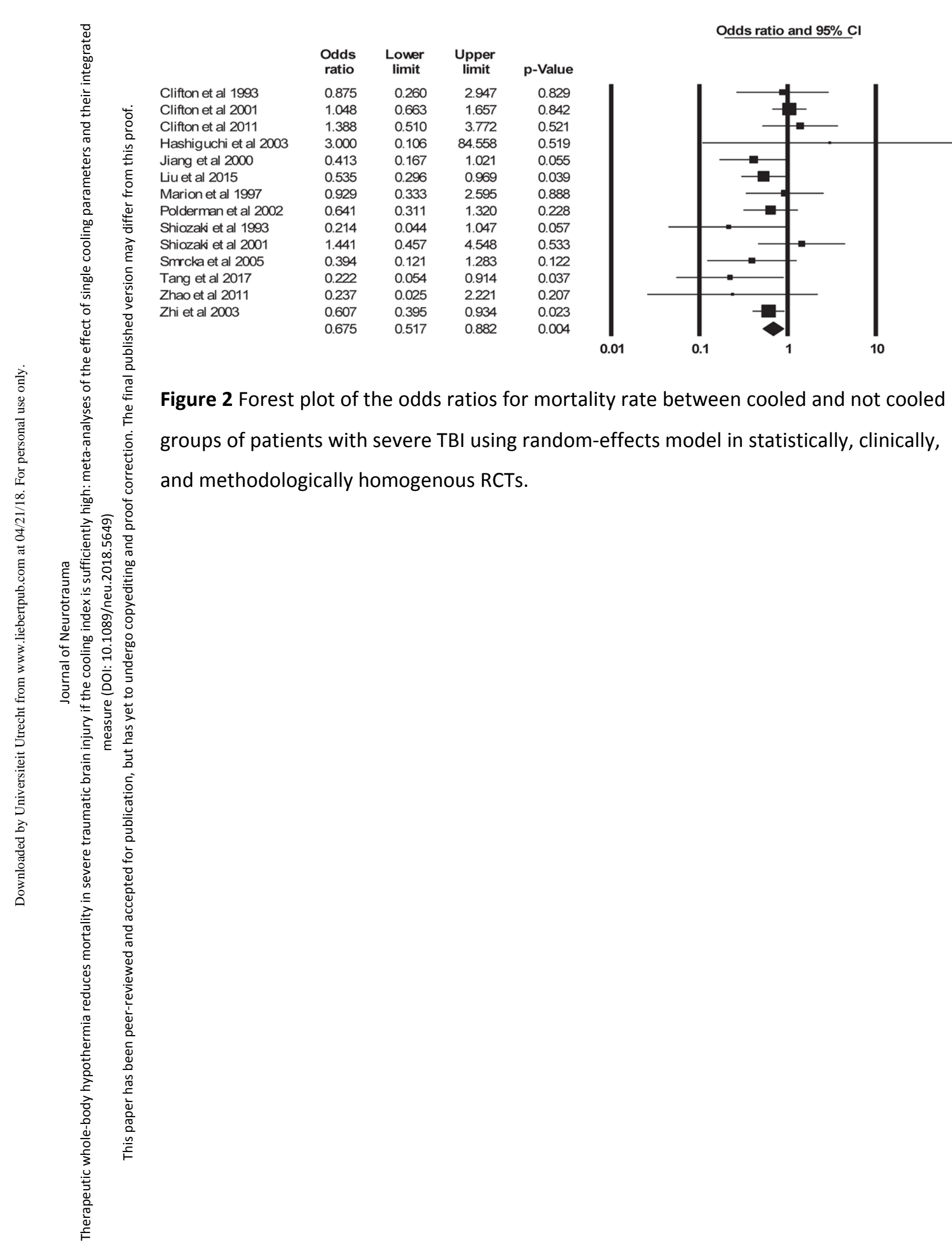




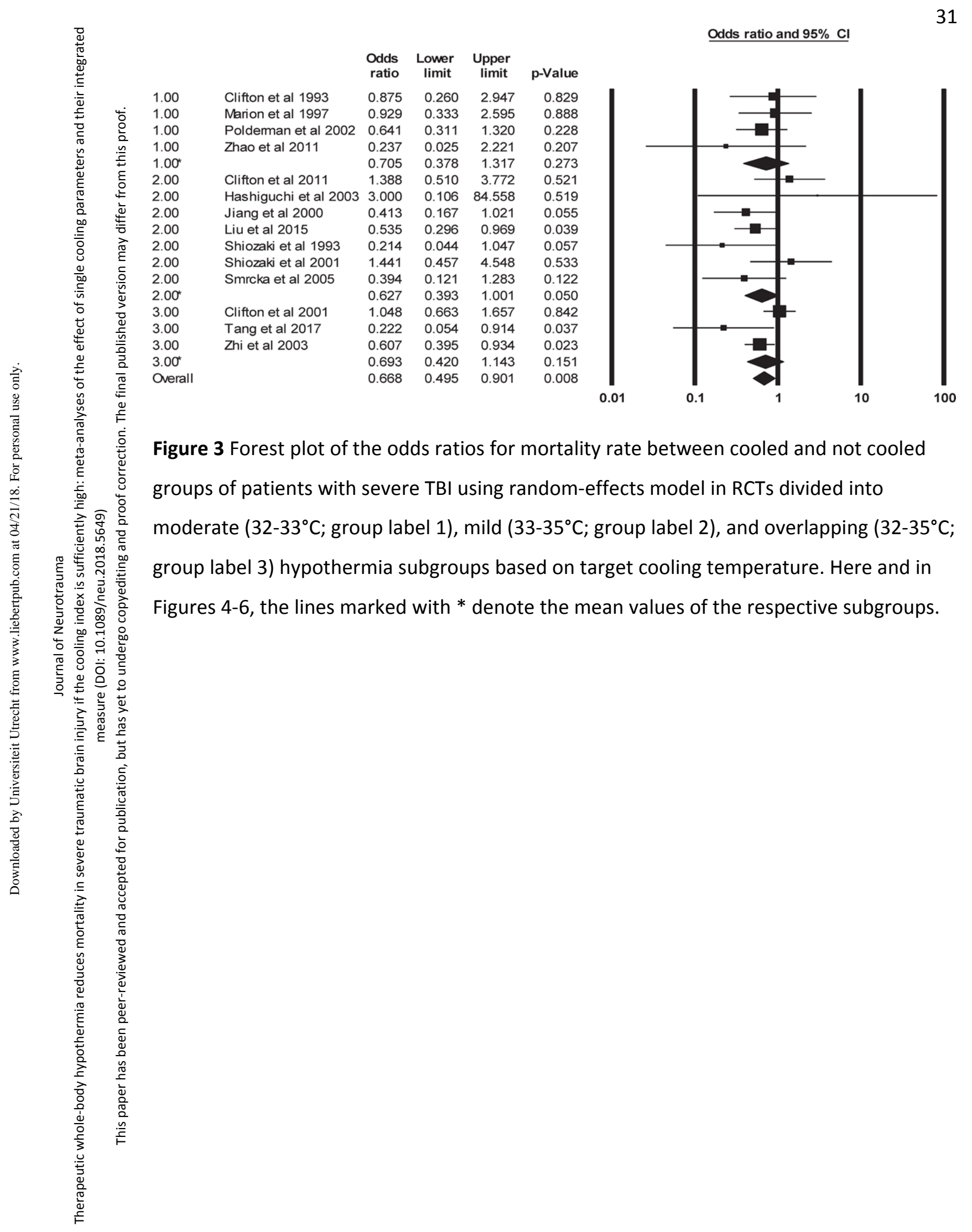




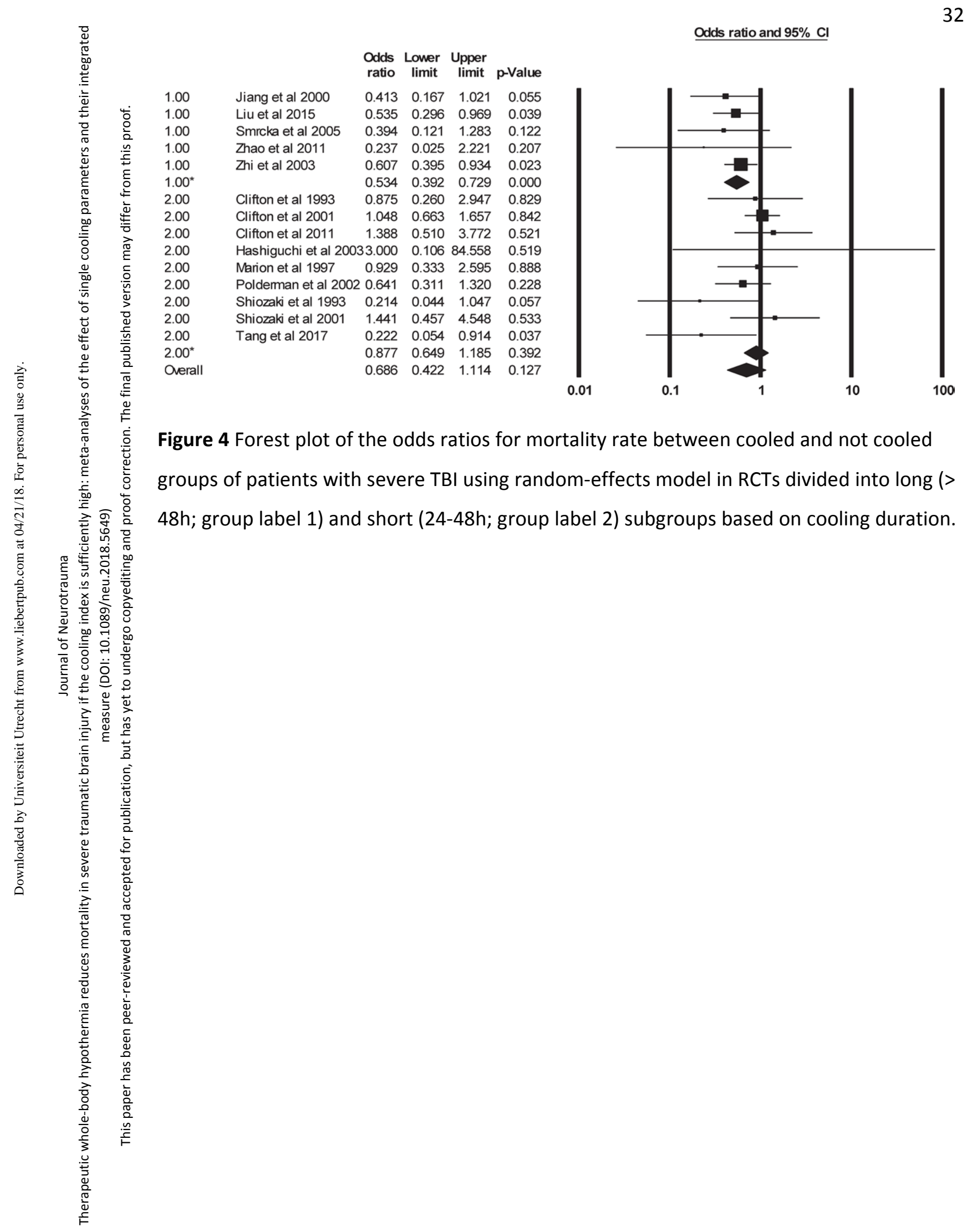




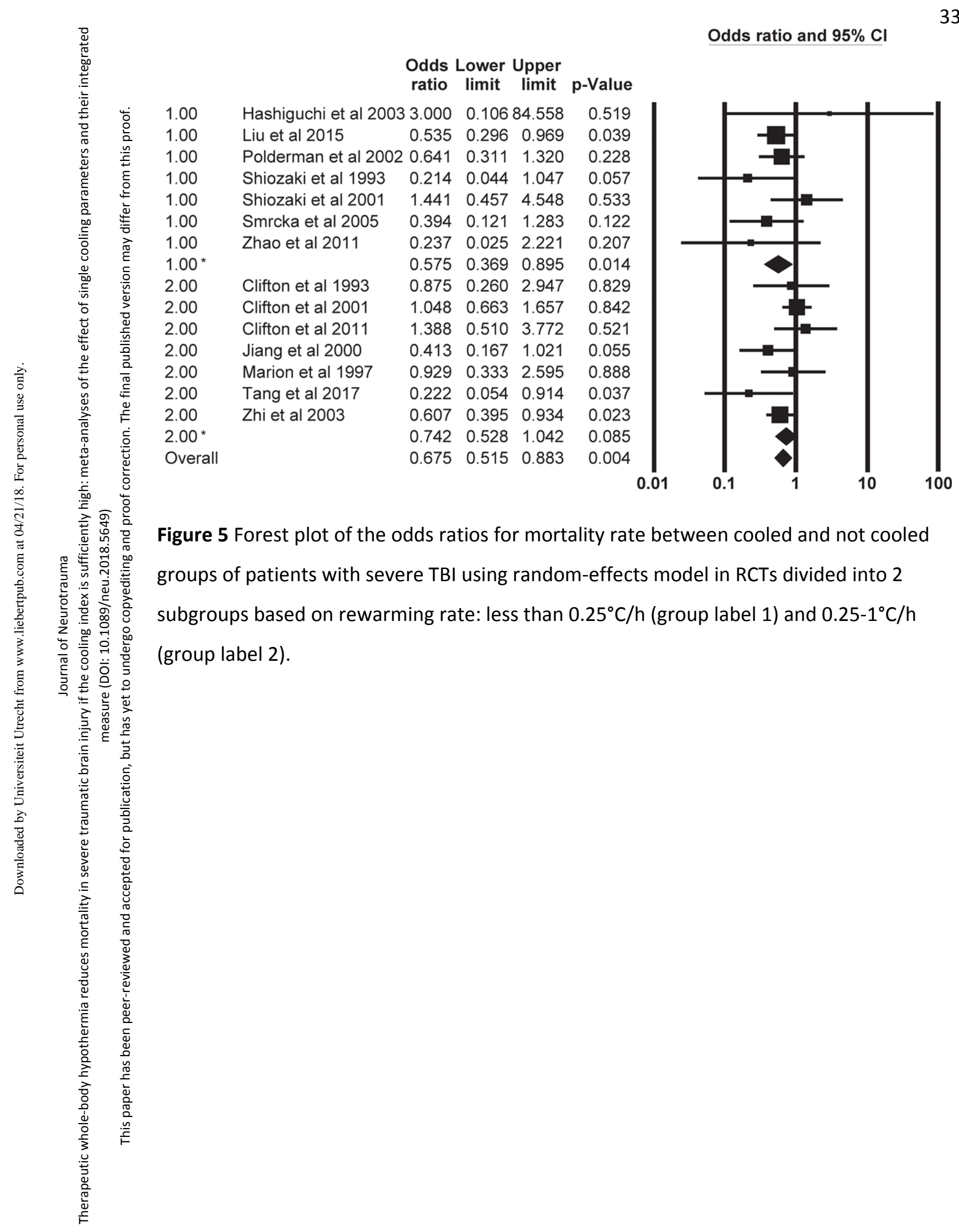




$\begin{array}{lcccc} & \begin{array}{c}\text { Odds } \\ \text { ratio }\end{array} & \begin{array}{c}\text { Lower } \\ \text { limit }\end{array} & \begin{array}{c}\text { Upper } \\ \text { limit }\end{array} & \text { p-Value } \\ \text { Hashiguchi et al 2003 } & 3.000 & 0.106 & 84.558 & 0.519 \\ \text { Marion et al 1997 } & 0.929 & 0.333 & 2.595 & 0.888 \\ \text { Shiozaki et al 2001 } & 1.441 & 0.457 & 4.548 & 0.533 \\ \text { Zhi et al 2003 } & 0.607 & 0.395 & 0.934 & 0.023 \\ & 0.831 & 0.462 & 1.493 & 0.535 \\ \text { Clifton et al 2001 } & 1.048 & 0.663 & 1.657 & 0.842 \\ \text { Clifton et al 2011 } & 1.388 & 0.510 & 3.772 & 0.521 \\ \text { Shiozak et al 1993 } & 0.214 & 0.044 & 1.047 & 0.057 \\ \text { Tang et al 2017 } & 0.222 & 0.054 & 0.914 & 0.037 \\ & 0.754 & 0.422 & 1.347 & 0.340 \\ \text { Clifton et al 1993 } & 0.875 & 0.260 & 2.947 & 0.829 \\ \text { Jiang et al 2000 } & 0.413 & 0.167 & 1.021 & 0.055 \\ \text { Smrcka et al 2005 } & 0.394 & 0.121 & 1.283 & 0.122 \\ \text { Zhao et al 2011 } & 0.237 & 0.025 & 2.221 & 0.207 \\ & 0.470 & 0.233 & 0.946 & 0.035 \\ & 0.686 & 0.455 & 1.033 & 0.071\end{array}$

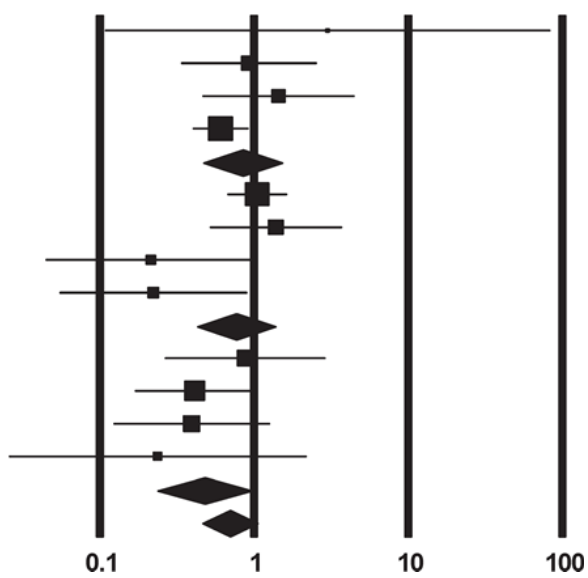

Figure 6 Forest plot of the odds ratios for mortality rate between cooled and not cooled groups of patients with severe TBI using random-effects model in RCTs divided into low (< $160^{\circ} \mathrm{C} \times \mathrm{h}$; group label 1$)$, moderate $\left(160-200^{\circ} \mathrm{C} \times \mathrm{h}\right.$; group label 2$)$, and high $\left(>200^{\circ} \mathrm{C} \times \mathrm{h}\right.$; group label 3) subgroups based on the cooling index. 


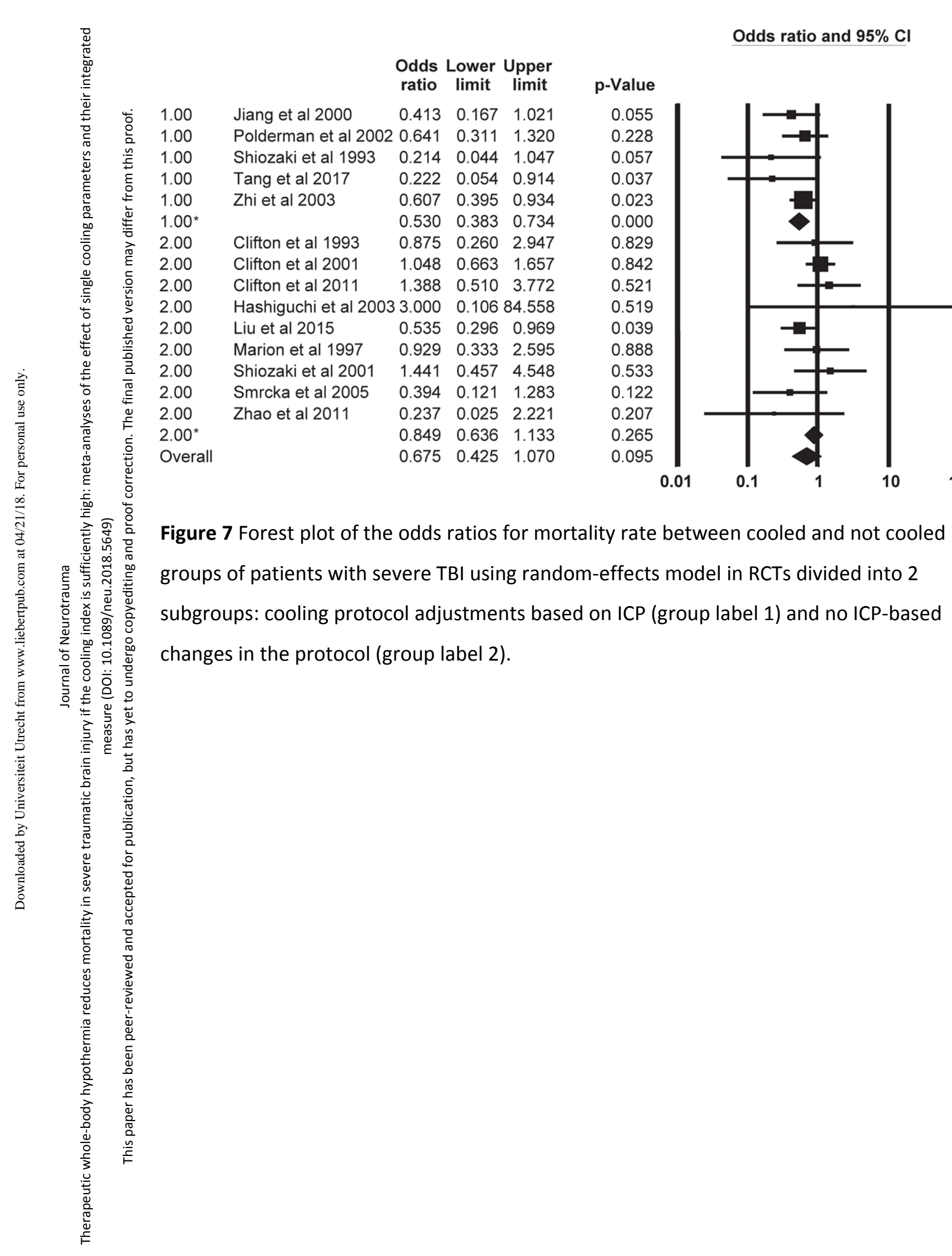




\section{Supplementary material}

\section{REFERENCES}

Andrews, P.J.D., Sinclair, H.L., Rodriguez, A., Harris, B.A., Battison, C.G., Rhodes, J.K.J., Murray, G.D. and Eurotherm Trial, C. (2015). Hypothermia for Intracranial Hypertension after Traumatic Brain Injury. N Engl J Med 373, 2403-2412.

Balvers, K., Van der Horst, M., Graumans, M., Boer, C., Binnekade, J.M., Goslings, J.C. and Juffermans, N.P. (2016). Hypothermia as a predictor for mortality in trauma patients at admittance to the Intensive Care Unit. J Emerg Trauma Shock 9, 97-102.

Bukur, M., Hadjibashi, A.A., Ley, E.J., Malinoski, D., Singer, M., Barmparas, G., Margulies, D. and Salim, A. (2012). Impact of prehospital hypothermia on transfusion requirements and outcomes. J Trauma Acute Care Surg 73, 1195-1201.

Clifton, G.L., Valadka, A., Zygun, D., Coffey, C.S., Drever, P., Fourwinds, S., Janis, L.S., Wilde, E., Taylor, P., Harshman, K., Conley, A., Puccio, A., Levin, H.S., McCauley, S.R., Bucholz, R.D., Smith, K.R., Schmidt, J.H., Scott, J.N., Yonas, H. and Okonkwo, D.O. (2011). Very early hypothermia induction in patients with severe brain injury (the National Acute Brain Injury Study: Hypothermia II): a randomised trial. Lancet Neurology 10, 131-139.

Clifton, G.L., Allen, S., Barrodale, P., Plenger, P., Berry, J., Koch, S., Fletcher, J., Hayes, R.L. and Choi, S.C. (1993). A phase II study of moderate hypothermia in severe brain injury. J Neurotrauma 10, 263-271.

Harris, O.A., Muh, C.R., Surles, M.C., Pan, Y., Rozycki, G., Macleod, J. and Easley, K. (2009). Discrete cerebral hypothermia in the management of traumatic brain injury: a randomized controlled trial Clinical article. J Neurosurg 110, 1256-1264.

Hashiguchi, N., Shiozaki, T., Ogura, H., Tanaka, H., Koh, T., Noborio, M., Fugita, K., Akimau, P., Kuwagata, Y., Shimazu, T. and Sugimoto, H. (2003). Mild hypothermia reduces 
expression of heat shock protein 60 in leukocytes from severely head-injured patients. J Trauma 55, 1054-1060.

Hifumi, T., Kuroda, Y., Kawakita, K., Yamashita, S., Oda, Y., Dohi, K., Maekawa, T. and Brain Hypothermia, B.H.S.G. (2016). Fever Control Management Is Preferable to Mild Therapeutic Hypothermia in Traumatic Brain Injury Patients with Abbreviated Injury Scale 3-4: A Multi-Center, Randomized Controlled Trial. J Neurotrauma 33, 1047-1053.

Jiang, J.Y., Yu, M.K. and Zhu, C. (2000). Effect of long-term mild hypothermia therapy in patients with severe traumatic brain injury: 1-year follow-up review of 87 cases. J Neurosurg 93, 546-549.

Lee, H.C., Chuang, H.C., Cho, D.Y., Cheng, K.F., Lin, P.H. and Chen, C.C. (2010). Applying Cerebral Hypothermia and Brain Oxygen Monitoring in Treating Severe Traumatic Brain Injury. World Neurosurg 74, 654-660.

Liu, W.G., Qiu, W.S., Zhang, Y., Wang, W.M., Lu, F. and Yang, X.F. (2006). Effects of selective brain cooling in patients with severe traumatic brain injury: a preliminary study. J Int Med Res 34, 58-64.

Liu, Y.H., Shang, Z.D., Chen, C., Lu, N., Liu, Q.F., Liu, M. and Yan, J. (2015). 'Cool and quiet' therapy for malignant hyperthermia following severe traumatic brain injury: A preliminary clinical approach. Exp Ther Med 9, 464-468.

Maekawa, T., Yamashita, S., Nagao, S., Hayashi, N., Ohashi, Y. and Brain-Hypothermia, B.H.S.G. (2015). Prolonged Mild Therapeutic Hypothermia versus Fever Control with Tight Hemodynamic Monitoring and Slow Rewarming in Patients with Severe Traumatic Brain Injury: A Randomized Controlled Trial. J Neurotrauma 32, 422-429. 
Marion, D.W., Penrod, L.E., Kelsey, S.F., Obrist, W.D., Kochanek, P.M., Palmer, A.M.,

Wisniewski, S.R. and DeKosky, S.T. (1997). Treatment of traumatic brain injury with moderate hypothermia. N Engl J Med 336, 540-546.

Polderman, K.H., Joe, R.T.T., Peerdeman, S.M., Vandertop, W.P. and Girbes, A.R.J. (2002). Effects of therapeutic hypothermia on intracranial pressure and outcome in patients with severe head injury. Intensive Care Med 28, 1563-1573.

Qiu, W., Zhang, Y., Sheng, H., Zhang, J.M., Wang, W.M., Liu, W.G., Chen, K.Y., Zhou, J.F. and Xu, Z.F. (2007). Effects of therapeutic mild hypothermia on patients with severe traumatic brain injury after craniotomy. J Crit Care 22, 229-235.

Rincon, F., Hunter, K., Schorr, C., Dellinger, R.P. and Zanotti-Cavazzoni, S. (2014). The epidemiology of spontaneous fever and hypothermia on admission of brain injury patients to intensive care units: a multicenter cohort study. J Neurosurg 121, 950-960.

Shiozaki, T., Hayakata, T., Taneda, M., Nakajima, Y., Hashiguchi, N., Fujimi, S., Nakamori, Y., Tanaka, H., Shimazu, T., Sugimoto, H. and Mild Hypothermia Study Grp, J. (2001). A multicenter prospective randomized controlled trial of the efficacy of mild hypothermia for severely head injured patients with low intracranial pressure. J Neurosurg 94, 50-54.

Shiozaki, T., Sugimoto, H., Taneda, M., Yoshida, H., Iwai, A., Yoshioka, T. and Sugimoto, T. (1993). Effect of mild hypothermia on uncontrollable intracranial hypertension after severe head-injury. J Neurosurg 79, 363-368.

Smrcka, M., Vidlák, M., Máca, K., Smrcka, V. and Gál, R. (2005). The influence of mild hypothermia on ICP, CPP and outcome in patients with primary and secondary brain injury. Acta Neurochir Suppl 95, 273-275.

Suehiro, E., Koizumi, H., Fujisawa, H., Fujita, M., Kaneko, T., Oda, Y., Yamashita, S., Tsuruta, R., Maekawa, T. and Suzuki, M. (2015). Diverse Effects of Hypothermia Therapy in Patients 
with Severe Traumatic Brain Injury Based on the Computed Tomography Classification of the Traumatic Coma Data Bank. J Neurotrauma 32, 353-358.

Suehiro, E., Koizumi, H., Kunitsugu, I., Fujisawa, H. and Suzuki, M. (2014). Survey of Brain Temperature Management in Patients with Traumatic Brain Injury in the Japan Neurotrauma Data Bank. J Neurotrauma 31, 315-320.

Tang, C.H., Bao, Y., Qi, M., Zhou, L.Z., Liu, F., Mao, J., Lei, Q.M., Qi, S.T. and Qiu, B.H. (2017). Mild induced hypothermia for patients with severe traumatic brain injury after decompressive craniectomy. J Crit Care 39, 267-270.

Tohme, S., Delhumeau, C., Zuercher, M., Haller, G. and Walder, B. (2014). Prehospital risk factors of mortality and impaired consciousness after severe traumatic brain injury: an epidemiological study. Scand J Trauma Resusc Emerg Med 22.

Zhao, Q.J., Zhang, X.G. and Wang, L.X. (2011). Mild hypothermia therapy reduces blood glucose and lactate and improves neurologic outcomes in patients with severe traumatic brain injury. J Crit Care 26, 311-315.

Zhi, D.S., Zhang, S. and Lin, X. (2003). Study on therapeutic mechanism and clinical effect of mild hypothermia in patients with severe head injury. Surg Neurol 59, 381-385. 


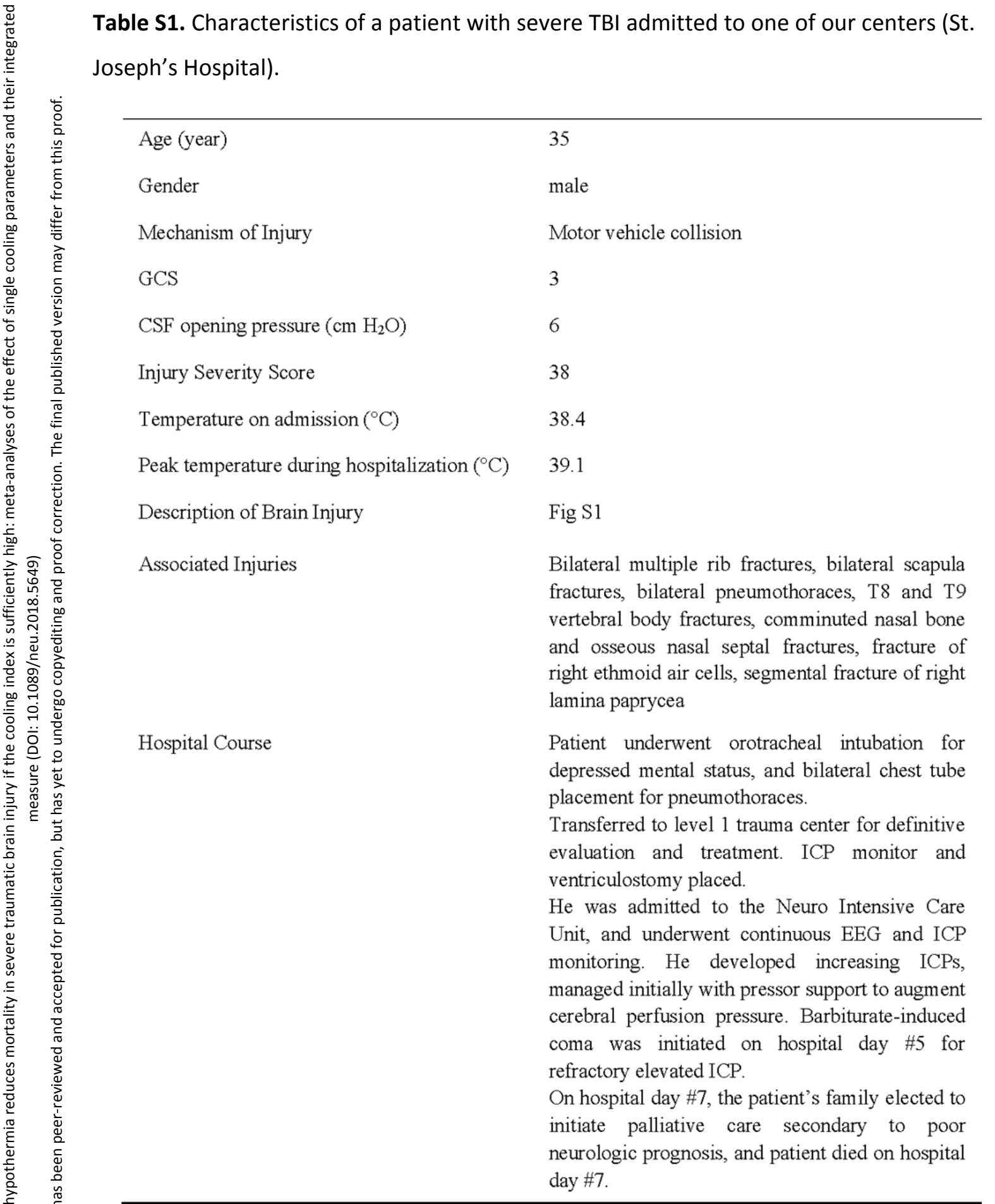


Table S2. PRISMA checklist.

$$
\text { Section/topic \# } \text { Checklist item }
$$


Page 42 of 52

\begin{tabular}{|c|c|c|c|}
\hline $\begin{array}{l}\text { Summary } \\
\text { measures }\end{array}$ & 13 & $\begin{array}{l}\text { State the principal summary measures (e.g., risk ratio, difference in } \\
\text { means). }\end{array}$ & $11-12$ \\
\hline $\begin{array}{l}\text { Synthesis of } \\
\text { results }\end{array}$ & 14 & $\begin{array}{l}\text { Describe the methods of handling data and combining results of } \\
\text { studies, if done, including measures of consistency (e.g., } I^{2} \text { ) for } \\
\text { each meta-analysis. }\end{array}$ & $7-10$ \\
\hline $\begin{array}{l}\text { Risk of bias } \\
\text { across studies }\end{array}$ & 15 & $\begin{array}{l}\text { Specify any assessment of risk of bias that may affect the } \\
\text { cumulative evidence (e.g., publication bias, selective reporting } \\
\text { within studies). }\end{array}$ & $10-11$ \\
\hline $\begin{array}{l}\text { Additional } \\
\text { analyses }\end{array}$ & 16 & $\begin{array}{l}\text { Describe methods of additional analyses (e.g., sensitivity or } \\
\text { subgroup analyses, meta-regression), if done, indicating which } \\
\text { were pre-specified. }\end{array}$ & $11-12$ \\
\hline \multicolumn{4}{|l|}{ RESULTS } \\
\hline Study selection & 17 & $\begin{array}{l}\text { Give numbers of studies screened, assessed for eligibility, and } \\
\text { included in the review, with reasons for exclusions at each stage, } \\
\text { ideally with a flow diagram. }\end{array}$ & 13-14; Figure 1 \\
\hline $\begin{array}{l}\text { Study } \\
\text { characteristics }\end{array}$ & 18 & $\begin{array}{l}\text { For each study, present characteristics for which data were } \\
\text { extracted (e.g., study size, PICOS, follow-up period) and provide } \\
\text { the citations. }\end{array}$ & $14-15$ \\
\hline $\begin{array}{l}\text { Risk of bias } \\
\text { within studies }\end{array}$ & 19 & $\begin{array}{l}\text { Present data on risk of bias of each study and, if available, any } \\
\text { outcome level assessment (see item 12). }\end{array}$ & 13-14; Table S3 \\
\hline $\begin{array}{l}\text { Results of } \\
\text { individual } \\
\text { studies }\end{array}$ & 20 & $\begin{array}{l}\text { For all outcomes considered (benefits or harms), present, for each } \\
\text { study: (a) simple summary data for each intervention group (b) } \\
\text { effect estimates and confidence intervals, ideally with a forest plot. }\end{array}$ & $\begin{array}{l}\text { 13-17; } \\
\text { Figures } 2-7 \text { and } \\
\text { S3-S5 }\end{array}$ \\
\hline $\begin{array}{l}\text { Synthesis of } \\
\text { results }\end{array}$ & 21 & $\begin{array}{l}\text { Present results of each meta-analysis done, including confidence } \\
\text { intervals and measures of consistency. }\end{array}$ & $\begin{array}{l}13-17 ; \text { Figures } \\
2-7\end{array}$ \\
\hline $\begin{array}{l}\text { Risk of bias } \\
\text { across studies }\end{array}$ & 22 & $\begin{array}{l}\text { Present results of any assessment of risk of bias across studies } \\
\text { (see Item 15). }\end{array}$ & 13-15; Table S3 \\
\hline $\begin{array}{l}\text { Additional } \\
\text { analysis }\end{array}$ & 23 & $\begin{array}{l}\text { Give results of additional analyses, if done (e.g., sensitivity or } \\
\text { subgroup analyses, meta-regression [see Item 16]). }\end{array}$ & $\begin{array}{l}16-17 ; \text { Figures } \\
6 \text { and } S 2\end{array}$ \\
\hline \multicolumn{4}{|l|}{ DISCUSSION } \\
\hline $\begin{array}{l}\text { Summary of } \\
\text { evidence }\end{array}$ & 24 & $\begin{array}{l}\text { Summarize the main findings including the strength of evidence for } \\
\text { each main outcome; consider their relevance to key groups (e.g., } \\
\text { healthcare providers, users, and policy makers). }\end{array}$ & $18-23$ \\
\hline Limitations & 25 & $\begin{array}{l}\text { Discuss limitations at study and outcome level (e.g., risk of bias), } \\
\text { and at review-level (e.g., incomplete retrieval of identified research, } \\
\text { reporting bias). }\end{array}$ & $18-19$ \\
\hline Conclusions & 26 & $\begin{array}{l}\text { Provide a general interpretation of the results in the context of other } \\
\text { evidence, and implications for future research. }\end{array}$ & $22-23$ \\
\hline \multicolumn{4}{|l|}{ FUNDING } \\
\hline Funding & 27 & $\begin{array}{l}\text { Describe sources of funding for the systematic review and other } \\
\text { support (e.g., supply of data); role of funders for the systematic } \\
\text { review. }\end{array}$ & 24 \\
\hline
\end{tabular}




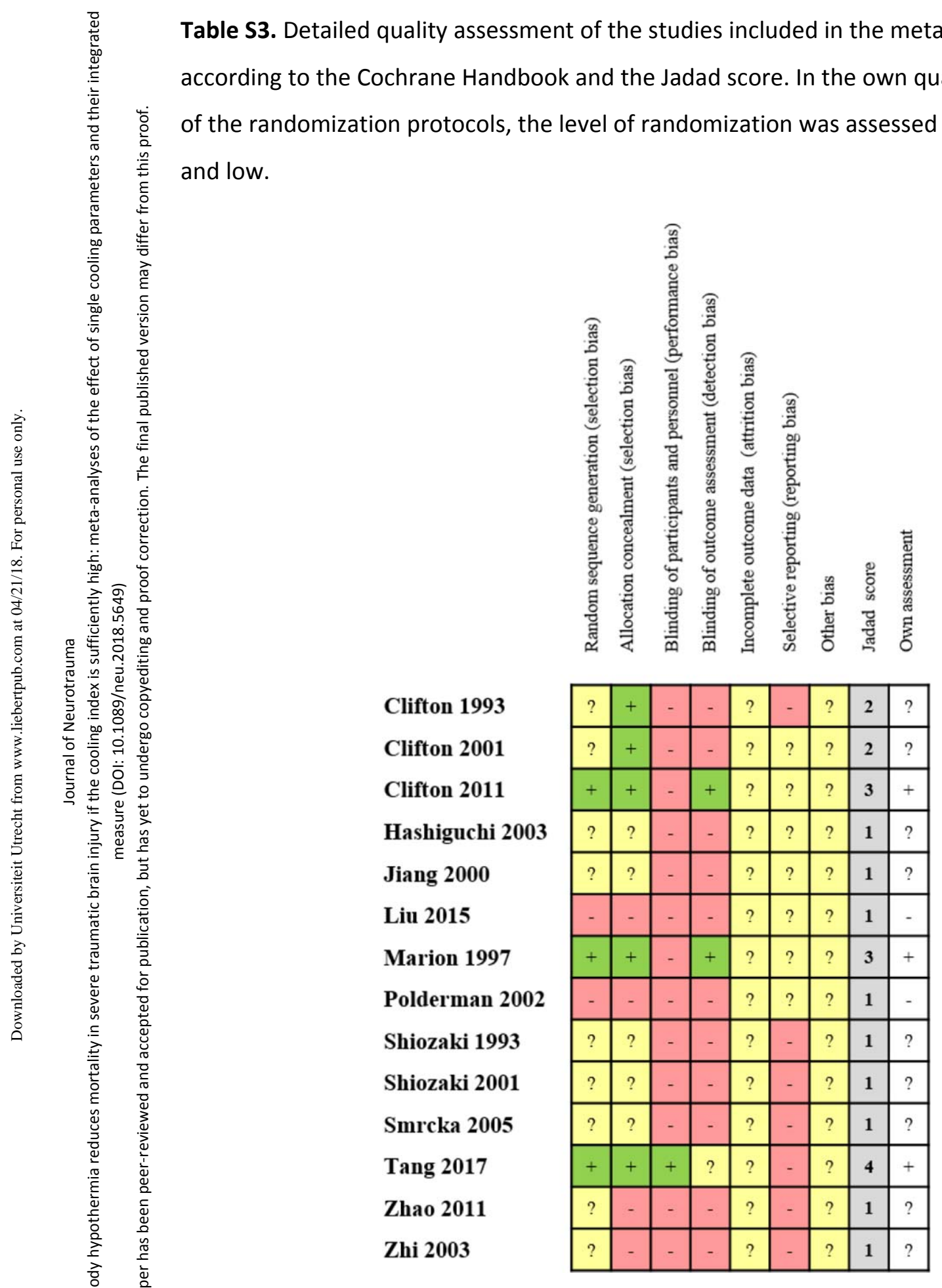




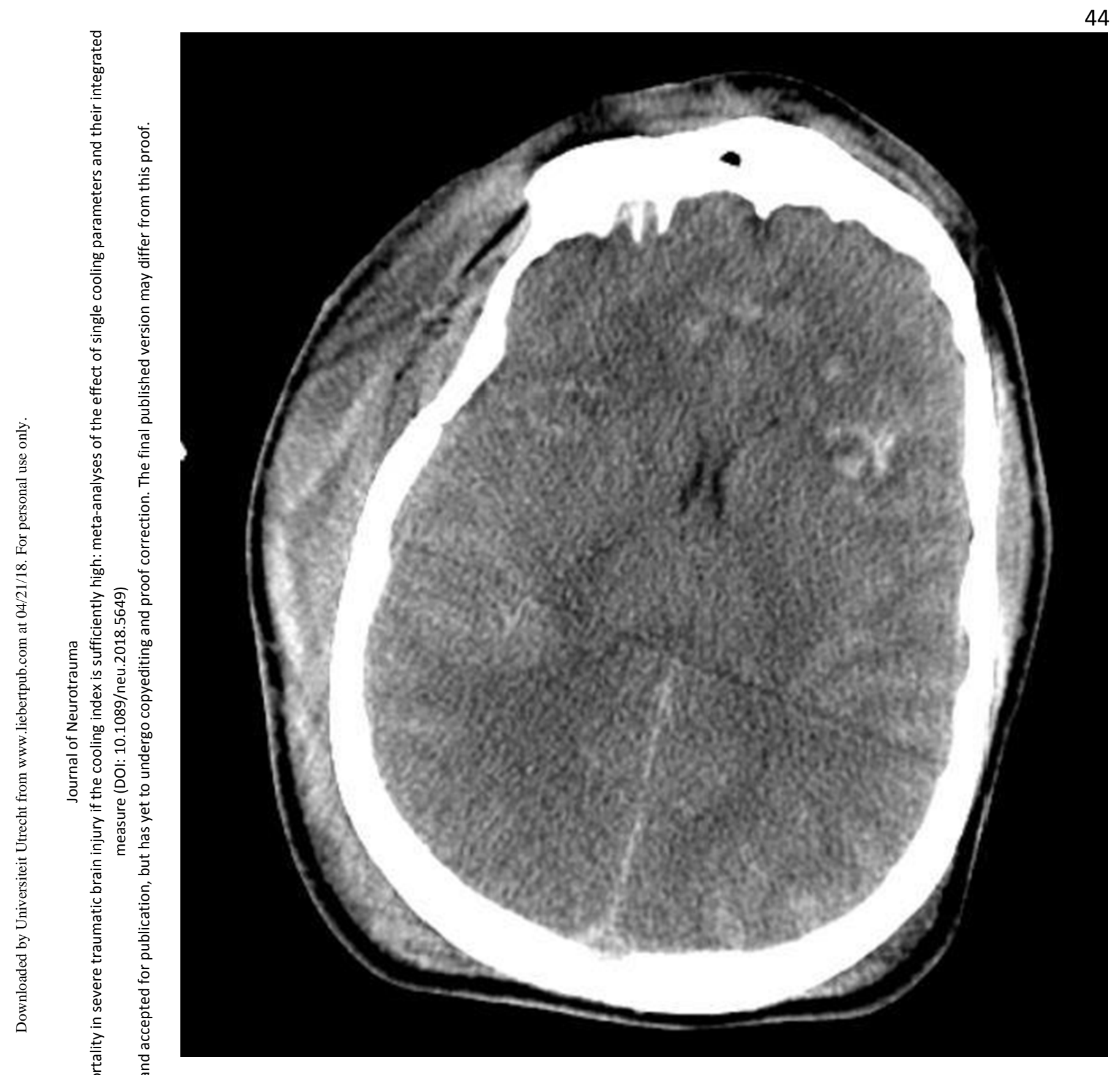

Figure S1. Axial CT image of the patient admitted with severe TBI, obtained at time of arrival to level 1 trauma center. TBI comprised diffuse bilateral subarachnoid hemorrhage, bilateral frontal contusions, small right subdural hematoma, and effacement of basal cisterns secondary to cerebral edema. 


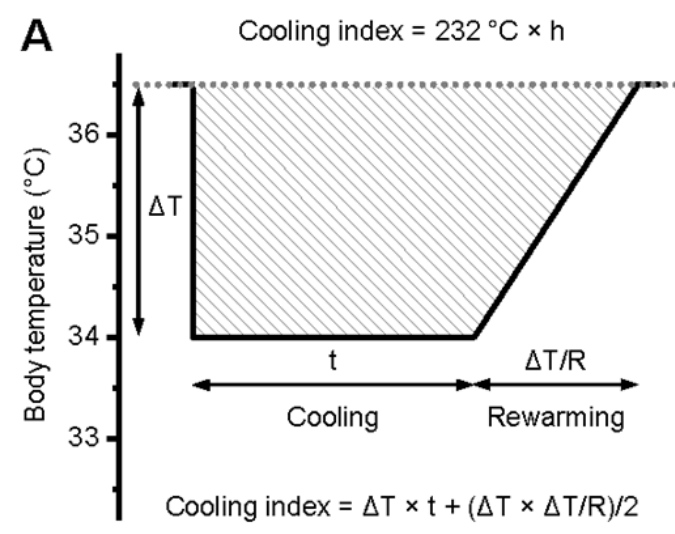

B Cooling index $=224^{\circ} \mathrm{C} \times \mathrm{h}$

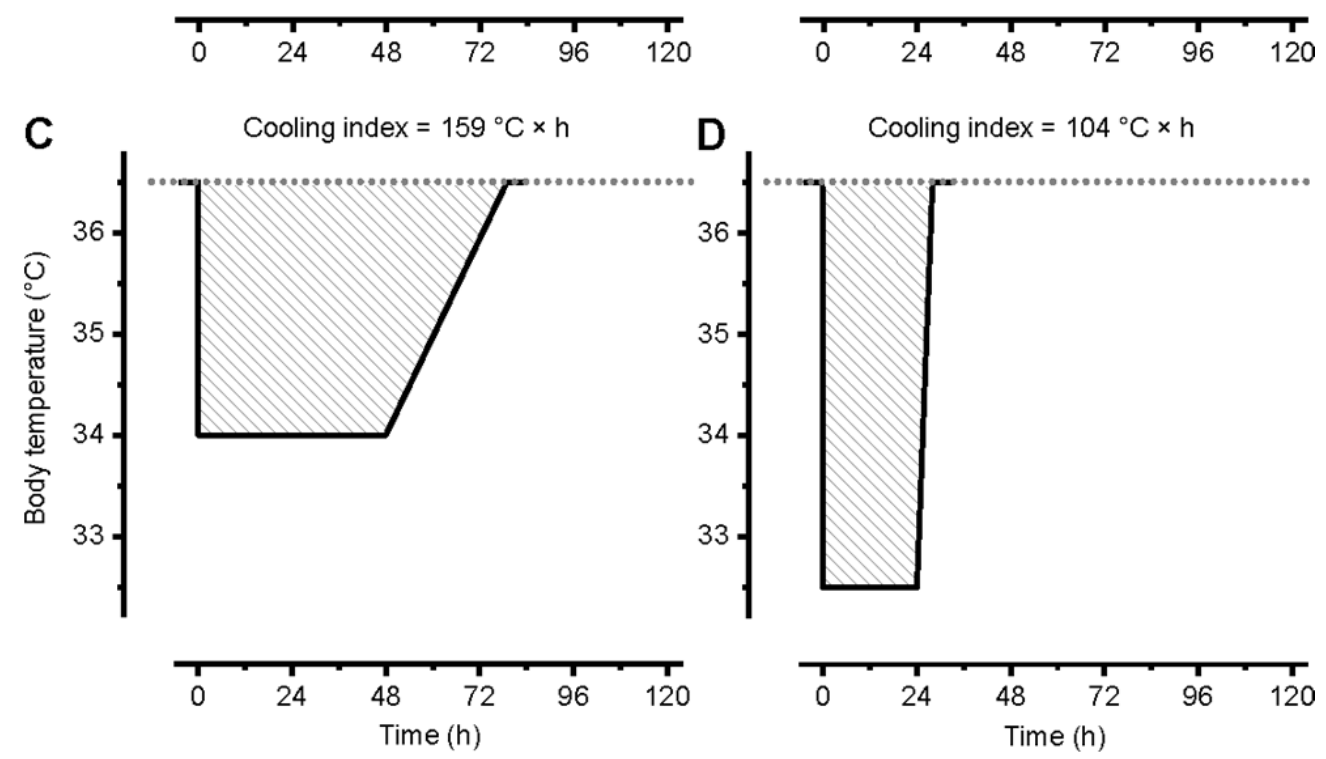

Figure S2. Calculation method of the cooling index and examples for high ( $\mathbf{A}$ and $\mathbf{B}$ ), moderate (C), and low (D) calculated values. The shown examples were calculated from the cooling parameters reported by Smrcka et al. (2005) (A), Clifton et al. (1993) (B), Shiozaki et al. (2001) (C), and Marion et al. (1997) (D). In all panels, the striped area represents the cooling index; the calculated values are indicated. Dotted gray line illustrates normal (not cooled) deep body temperature considered as $36.5^{\circ} \mathrm{C} . \Delta \mathrm{T}$, difference between normal body temperature and cooling target temperature; $t$, cooling duration; $R$, rate of rewarming. See main text for detailed explanation. 
Page 46 of 52

\begin{tabular}{lrrrr} 
& $\begin{array}{c}\text { Odds } \\
\text { ratio }\end{array}$ & $\begin{array}{c}\text { Lower } \\
\text { limit }\end{array}$ & \multicolumn{1}{c}{$\begin{array}{c}\text { Upper } \\
\text { imit }\end{array}$} & $\begin{array}{c}\text { Upper } \\
\text { limit }\end{array}$ \\
Andrews etal 2015 & 1.480 & 0.958 & 2287 & 2287 \\
Balvers etal 2016 & 3.796 & 2.655 & 5.427 & 5.427 \\
Bukur etal 2012 & 1.653 & 1.446 & 1.890 & 1.890 \\
Clifton et al 1993 & 0.875 & 0.260 & 2.947 & 2.947 \\
Clifton et al 2001 & 1.048 & 0.663 & 1.657 & 1.657 \\
Clifton et al 2011 & 1.388 & 0.510 & 3.772 & 3.772 \\
Harris etal 2009 & 2250 & 0.439 & 11.522 & 11.522 \\
Hashiguchi etal 2003 & 3.000 & 0.106 & 84.558 & 84.558 \\
Hifumietal 2016 & 4.817 & 1.268 & 18.302 & 18.302 \\
Jiang etal 2000 & 0.413 & 0.167 & 1.021 & 1.021 \\
Lee etal 2010 & 0.500 & 0.041 & 6.166 & 6.166 \\
Liu etal 2006 & 0.367 & 0.105 & 1281 & 1281 \\
Liu etal 2015 & 0.535 & 0.296 & 0.969 & 0.969 \\
Maekawa etal 2015 & 1.820 & 0.822 & 4.031 & 4.031 \\
Marion etal 1997 & 0.929 & 0.333 & 2.595 & 2.595 \\
Polderman etal 2002 & 0.641 & 0.311 & 1.320 & 1.320 \\
Ciu etal 2007 & 0.603 & 0.223 & 1.630 & 1.630 \\
Rincon etal 2014 & 22.484 & 11.173 & 45246 & 45.246 \\
Shiozaki etal 1993 & 0214 & 0.044 & 1.047 & 1.047 \\
Shiozaki etal 2001 & 1.441 & 0.457 & 4.548 & 4.548 \\
Smrcka etal 2005 & 0.394 & 0.121 & 1283 & 1283 \\
Suehiro etal 2014 & 1.167 & 0.599 & 2273 & 2273 \\
Suehiro etal 2015 & 2.012 & 0.883 & 4.588 & 4.588 \\
Tangetal 2017 & 0.222 & 0.054 & 0.914 & 0.914 \\
Tohme etal 2014 & 2.054 & 1.377 & 3.064 & 3.064 \\
Zhao etal 2011 & 0.0237 & 0.025 & 2221 & 2221 \\
Zhi etal 2003 & 0.607 & 0.395 & 0.934 & 0.934 \\
& 1.164 & 0.840 & 1.611 & 1.611 \\
& & & &
\end{tabular}

Odds ratio and $95 \% \mathrm{Cl}$

Figure S3. Forest plot of the odds ratios for mortality rate between cooled and not cooled groups of patients with severe TBI using random-effects model in 27 trials of all study types. 


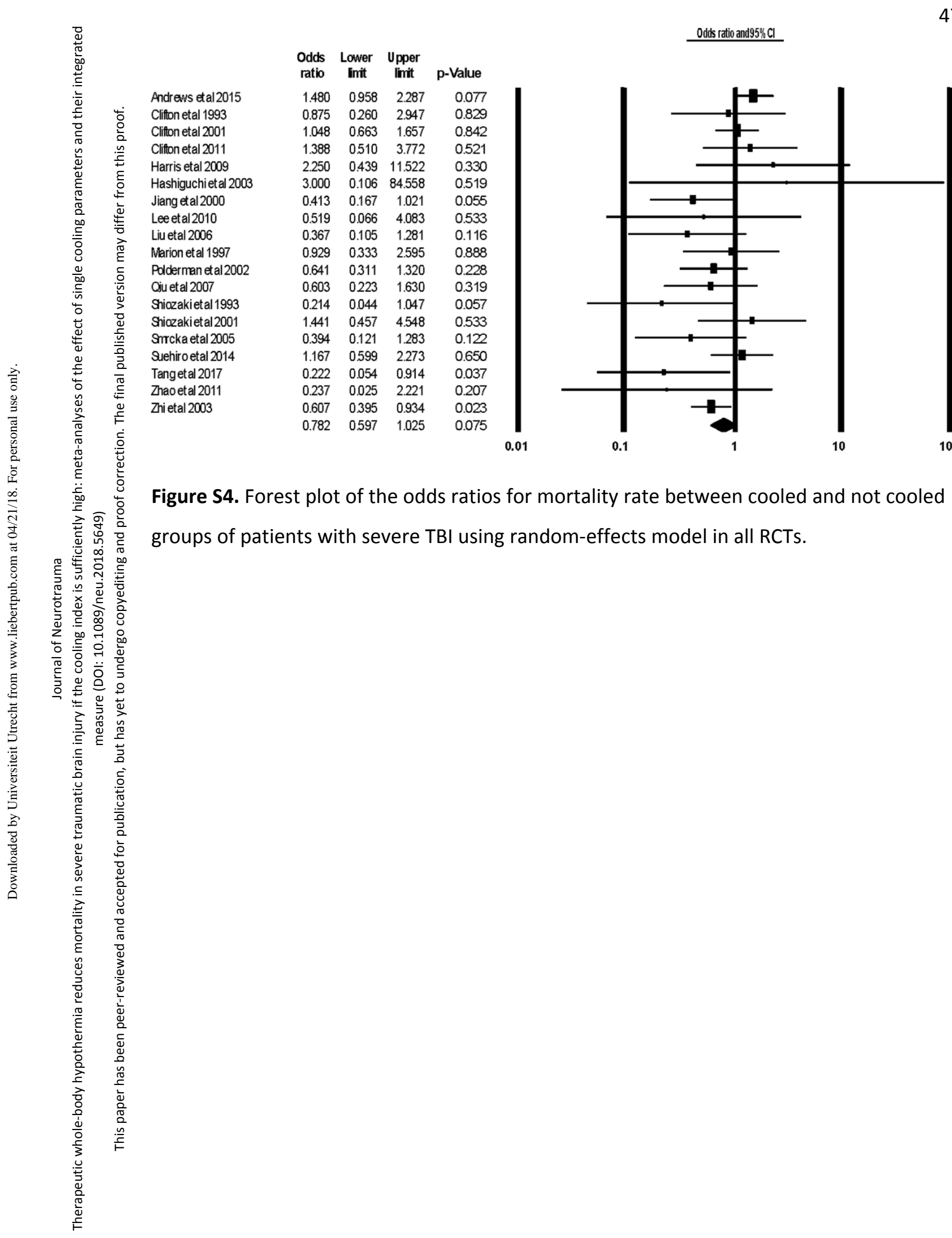




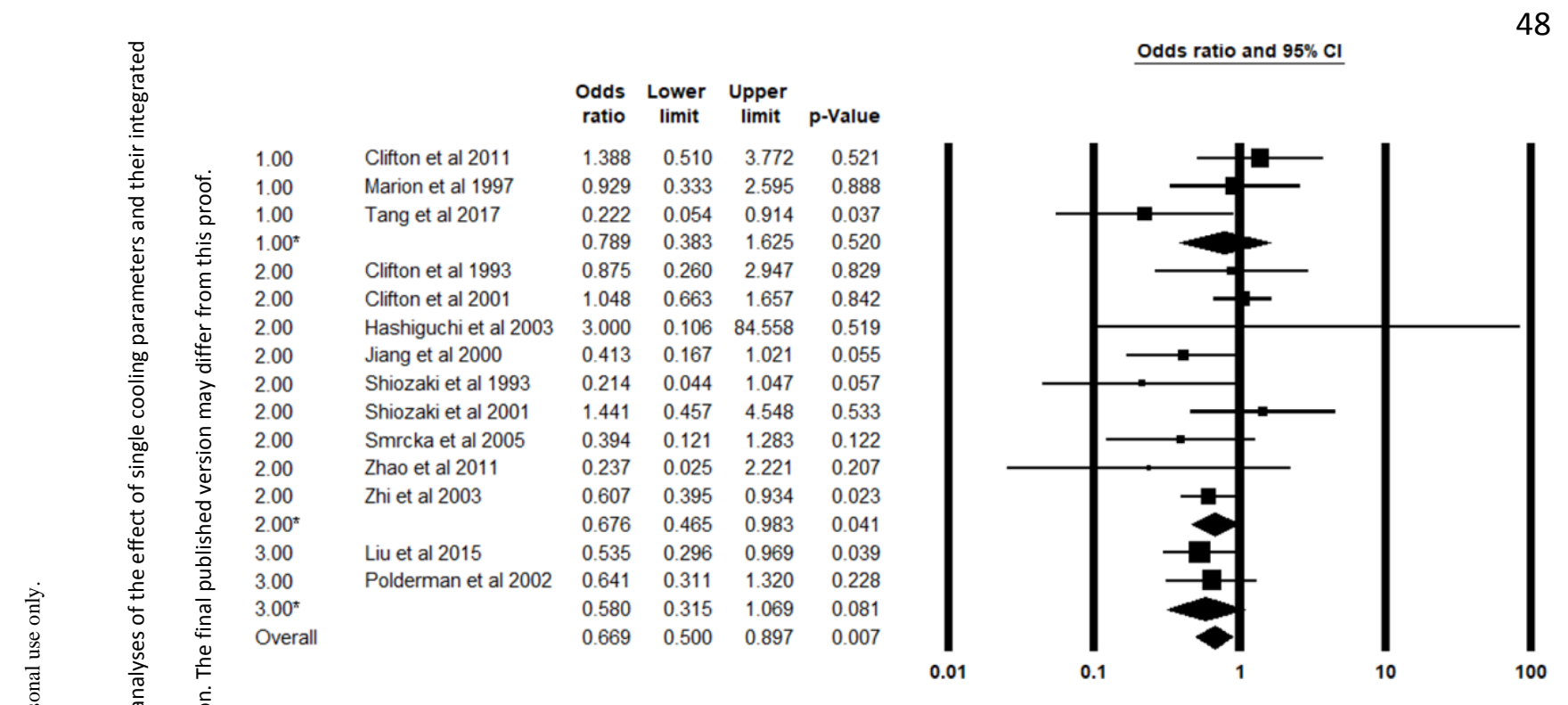

Figure S5. Forest plot of the odds ratios for mortality rate between cooled and not cooled groups of patients with severe TBI in RCT subgroups of good (group label 1), medium (group label 2), and low (group label 3) level of randomization protocols. The lines marked with * denote the mean values of the respective subgroups. 


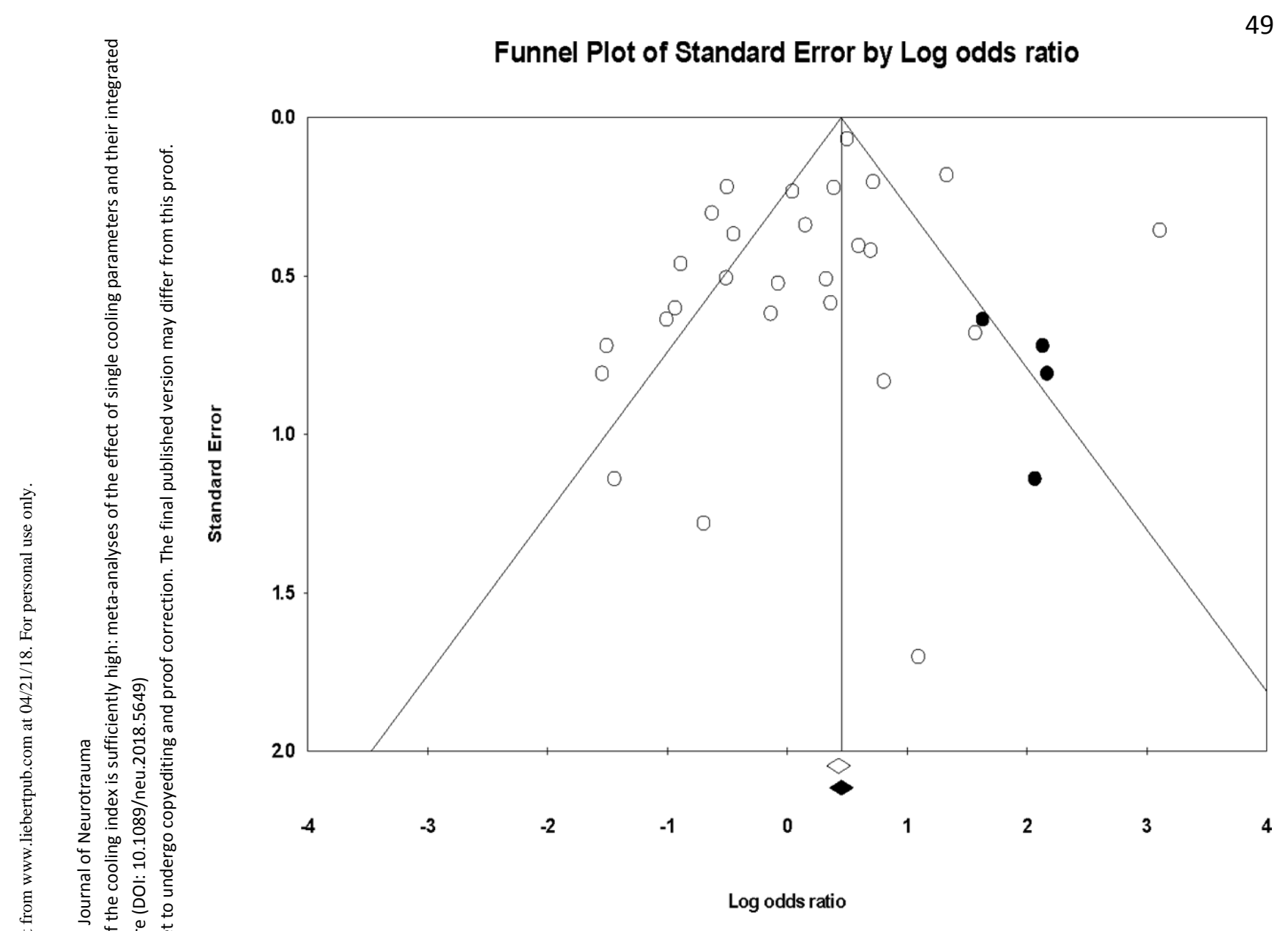

Figure S6. Funnel plot of 27 studies included in Figure S3.

Here, and in Figures S7-S9, open circles represent results from studies included in the forest plot, while closed circles indicate studies that appeared to be missing according to the trim and fill method of Duval and Tweedie. Open and closed diamonds represent the average estimated effect size without (open diamond) and with trim and fill correction (closed diamond). Duval and Tweedie corrected value: $1.37(95 \% \mathrm{Cl}, 1.00,1.88)$. 
Page 50 of 52

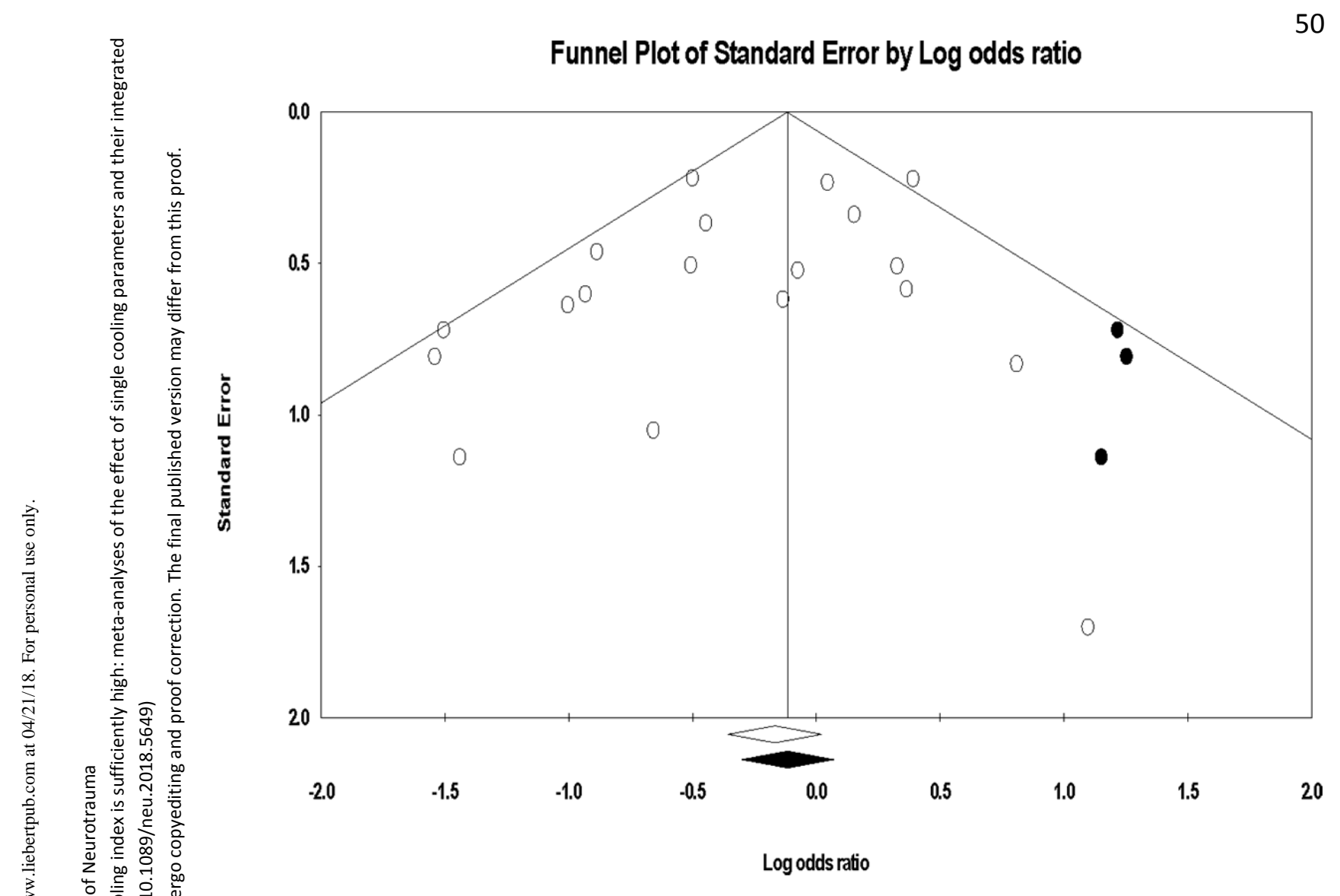

Figure S7. Funnel plot of 19 studies included in Figure S4. Duval and Tweedie trim and fill corrected value: $0.86(95 \% \mathrm{Cl}, 0.65,1.13)$. 


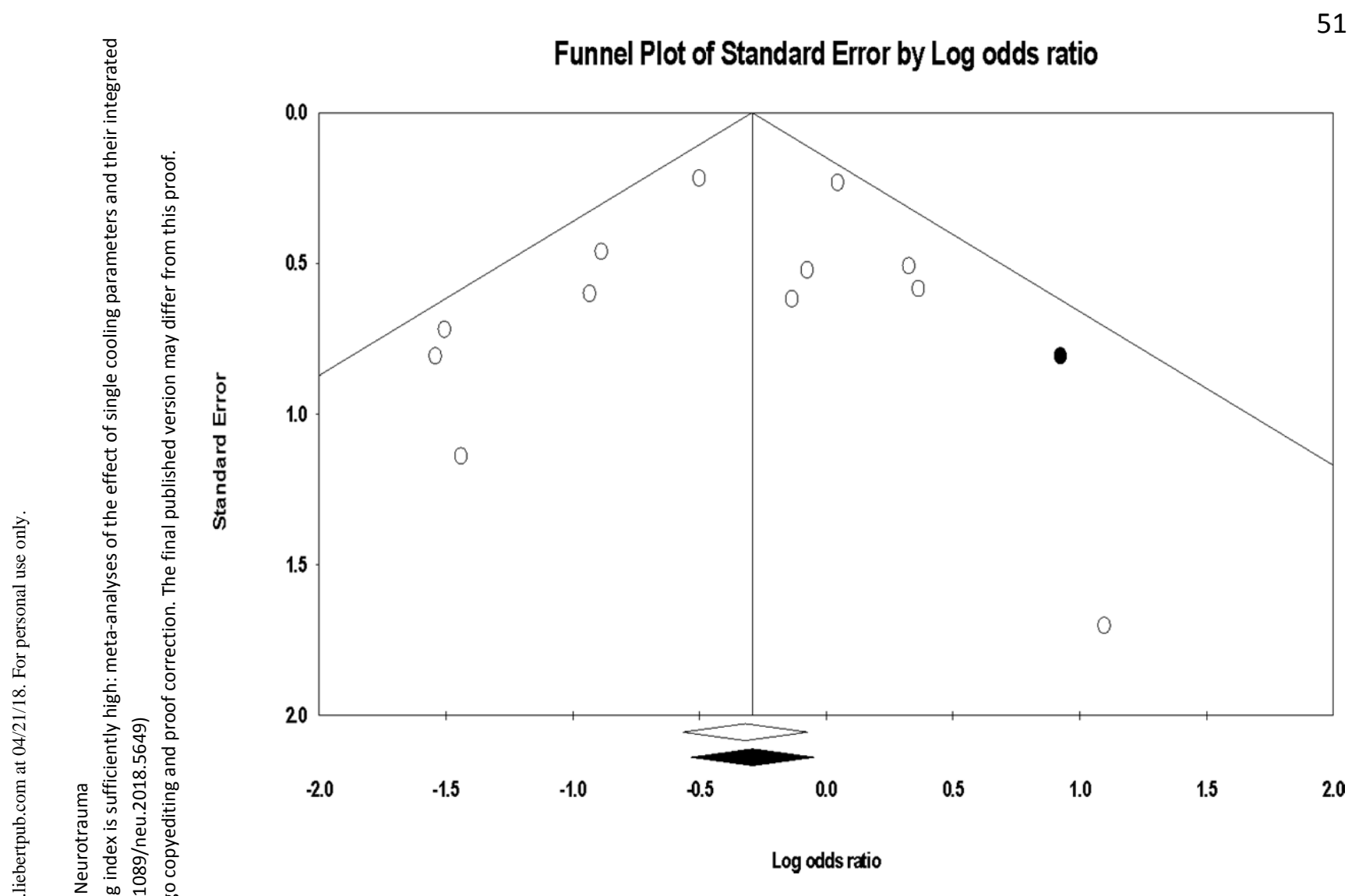

Figure S8. Funnel plot of 14 studies included in Figures 2-5, 7, and S5. Duval and Tweedie trim and fill corrected value: $0.70(95 \% \mathrm{Cl}, 0.53,0.92) ; \mathrm{p}=0.509$ with Egger's test. 
Page 52 of 52

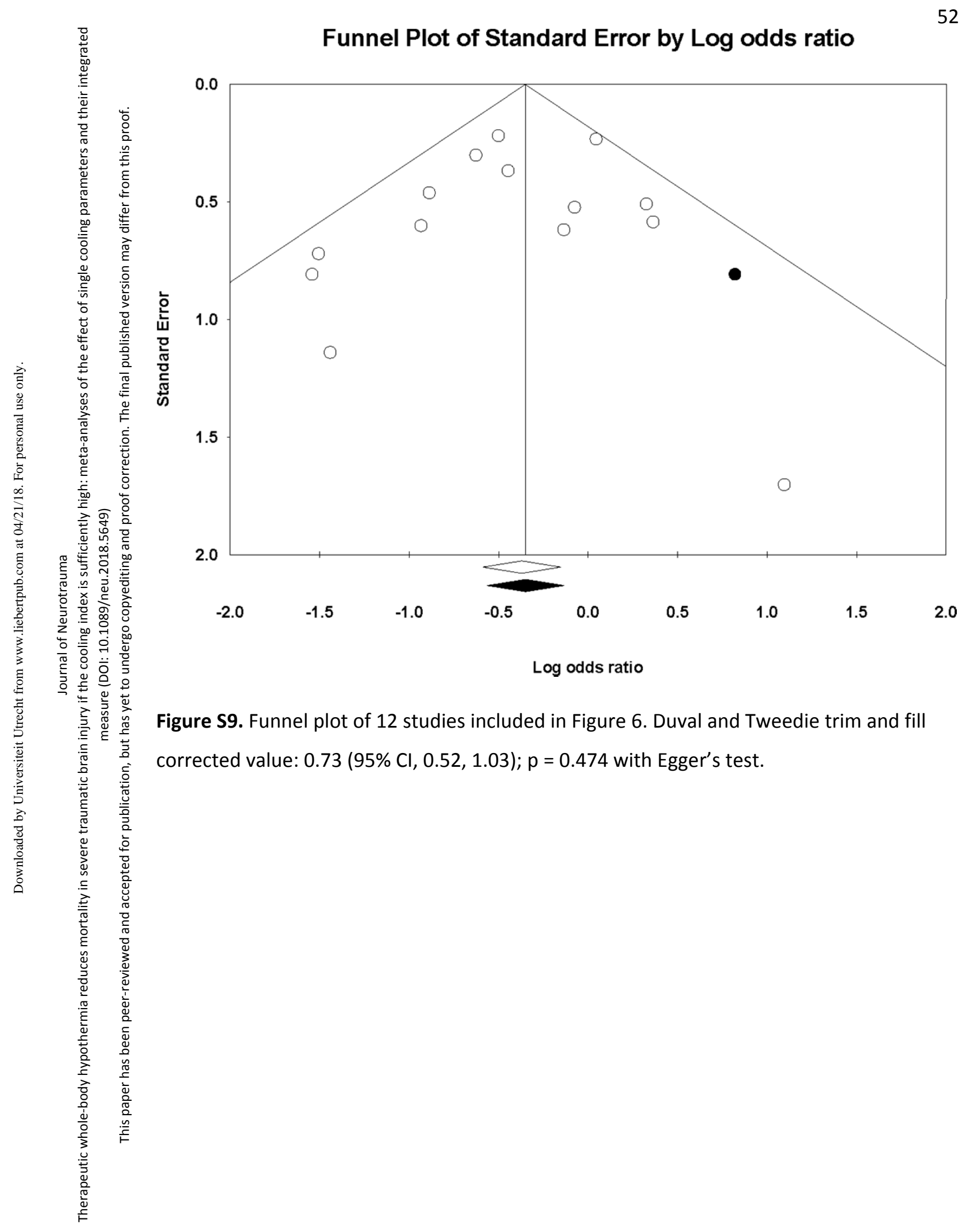

